\title{
Modelling inorganic material in activated sludge systems
}

\author{
Ekama GA* and Wentzel MC \\ Water Research Group, Department of Civil Engineering, University of Cape Town, Rondebosch, Cape 7707, South Africa
}

\section{Abstract}

\begin{abstract}
A simple predictive model for the activated sludge reactor inorganic suspended solids (ISS) concentration is presented. It is based on the accumulation of influent ISS in the reactor and an ordinary heterotrophic organism (OHO) ISS content $\left(\mathrm{f}_{\text {ооно }}\right)$ of $0.15 \mathrm{mg}$ ISS/mgOHOVSS and a variable phosphate accumulating organism (PAO) ISS content $\left(\mathrm{f}_{\mathrm{iPAO}}\right)$ proportional to their $\mathrm{P}$ content $\left(\mathrm{f}_{\mathrm{XBGP}}\right)$. The model is validated with data from 21 investigations conducted over the past 15 years on 30 aerobic and anoxic-aerobic nitrification denitrification (ND) systems and 18 anaerobic-anoxic-aerobic ND biological excess P removal (BEPR) systems variously fed artificial and real wastewater and operated from 3 to $20 \mathrm{~d}$ sludge age. The predicted reactor VSS/TSS ratio reflects the observed relative sensitivity to sludge age, which is low, and to BEPR, which is high. For effective use of the model for design, two significant issues require attention: measurement of the influent ISS concentration, which is not commonly done in wastewater characterisation analyses; and estimating a priori the P content of PAOs $\left(\mathrm{f}_{\mathrm{XBGP}}\right)$, which can vary considerably depending on the extent of anoxic P uptake BEPR that takes place in the system. Some guidance on selection of the mixed liquor VSS/TSS ratio for design is given.
\end{abstract}

Keywords: activated sludge, inorganic suspended solids, modelling, biological nutrient removal

\section{Abbreviations}

\begin{tabular}{|c|c|}
\hline er & $=$ Aerobic reactor \\
\hline An & $=$ Anaerobic reactor \\
\hline ANO & $=$ Autotrophic nitrifier organisms \\
\hline Art & $=$ Artificial wastewater \\
\hline AS & $=$ Activated sludge \\
\hline ASIM & $\begin{aligned}= & \text { Activated sludge simulation programme - a platform } \\
& \text { for using AS models }\end{aligned}$ \\
\hline ASM & $=$ Activated sludge model \\
\hline Ax & $=$ Anoxic reactor \\
\hline BEPR & $=$ Biological excess phosphorus removal \\
\hline BNR & $=$ Biological nutrient removal \\
\hline Cntl & $=$ Control \\
\hline COD & $=$ Chemical oxygen demand \\
\hline conc. & $=$ concentration \\
\hline $\operatorname{degC}$ & $=$ degrees Centigrade \\
\hline DSVI & $=$ Diluted sludge volume index \\
\hline Exp & $=$ Experimental \\
\hline FA & $=$ Fully aerobic \\
\hline FSA & $=$ free and saline ammonia \\
\hline $\mathrm{I} \#$ & $=$ Investigation number \\
\hline IAND & $\begin{array}{l}=\text { Intermittently aerated nitrification denitrification } \\
\text { system }\end{array}$ \\
\hline IDS & $=$ Inorganic dissolved solids \\
\hline ISS & $=$ Inorganic suspended solids \\
\hline IWA & $=$ International Water Association \\
\hline MLE & $\begin{array}{l}=\text { Modified Ludzack-Ettinger nitrification denitrification } \\
\text { system }\end{array}$ \\
\hline
\end{tabular}

* To whom all correspondence should be addressed.

政+2721650 2588/0/4; fax:+2721 6897471

e-mail: EKAMA@ebe.uct.ac.za

Received 17 September 2003; accepted in revised form 20 February 2004.

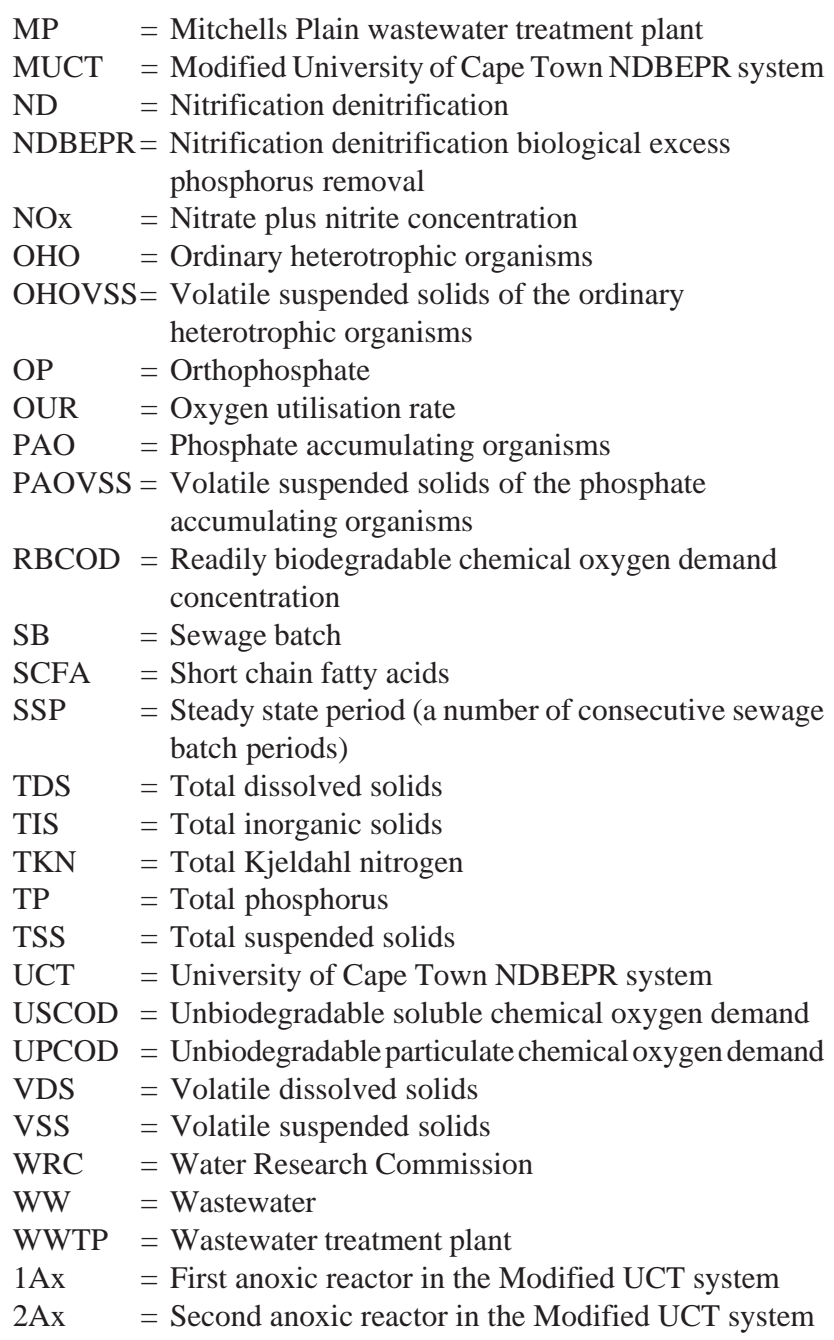




\section{Symbols}

$\mathrm{b}_{\mathrm{HT}}, \mathrm{b}_{\mathrm{GT}}=$ endogenous respiration rate for OHOs and PAOs at $\mathrm{T}^{\circ} \mathrm{C}$

$=0.24 / \mathrm{d}$ and $0.04 / \mathrm{d}$ respectively at $20^{\circ} \mathrm{C}\left(\theta_{\mathrm{b}}=1.029\right.$ for both)

$\mathrm{f}_{\text {avOHO }}, \mathrm{f}_{\text {avPAO }}=$ fraction of the VSS concentration which is OHOs and PAOs respectively

$\mathrm{f}_{\mathrm{B}} \quad=$ ISS/VSS ratio ( $\mathrm{mgISS} / \mathrm{mgVSS}$ ) of OHOs and their endogenous residue estimated by Wentzel et al. $(2002)=0.17 \mathrm{mgISS} / \mathrm{mgVSS}$

$\mathrm{f}_{\mathrm{cv}}=\mathrm{COD} / \mathrm{VSS}$ ratio of organics $=1.48 \mathrm{mgCOD} / \mathrm{mgVSS}$

$\mathrm{f}_{\mathrm{EH}}, \mathrm{f}_{\mathrm{EG}}=$ endogenous residue fraction of the OHOs and PAOs

$=0.20$ and 0.25 respectively

$\mathrm{f}_{\mathrm{i}} \quad=$ VSS/TSS ratio of reactor sludge mass.

$\mathrm{f}_{\text {іоно }} \quad=$ inorganic content of $\mathrm{OHO}$ cell mass

$=0.15 \mathrm{mgISS} / \mathrm{mgOHOVSS}$

$\mathrm{f}_{\mathrm{iPAO}}=$ total inorganic solids content of PAOs $\left(=\mathrm{f}_{\text {iPAOBM }}+\mathrm{f}_{\text {iPAOPP }}\right)$

$\mathrm{f}_{\text {iPAOBM }}=$ inorganic solids content of the PAO active biomass (without polyphosphate)(mgISS/mgVSS)

$=0.15 \mathrm{mgISS} / \mathrm{mgPAOVSS}$

$\mathrm{f}_{\text {iPAOPP }}=$ inorganic material content of the PAO polyphosphate (mgISS/mgVSS)

$\mathrm{f}_{\text {Sup }} \quad=$ influent unbiodegradable particulate COD fraction

$\mathrm{f}_{S^{\prime} \text { us }} \quad=$ influent unbiodegradable soluble COD fraction

$\mathrm{f}_{\mathrm{Sb} \text { 's }} \quad=$ influent readily biodegradable $(\mathrm{RB}) \mathrm{COD}$ fraction with respect to biodegradable COD.

$\mathrm{f}_{\mathrm{xa}} \quad=$ Anaerobic mass fraction

$\mathrm{f}_{\mathrm{XBGBM}} \quad=$ Pcontent of PAOcell mass (without polyphosphate)

$\mathrm{f}_{\text {XBGP }}$

$\mathrm{f}_{\text {XBGPBM }}$

$\mathrm{f}_{\mathrm{XBGPP}}$

$\mathrm{i}_{\text {TSSXBM }}$

$=$ total $P$ content of PAOs $\left(=\mathrm{f}_{\text {XBGPBM }}+\mathrm{f}_{\text {XBGPP }}\right)$

$=\mathrm{P}$ content of the $\mathrm{PAO}$ cell mass

$=0.03 \mathrm{mgP} / \mathrm{mgPAOVSS}$

= polyphosphate content of PAOs (mgpolyphosphate/ mgPAOVSS)

$=$ TSS to COD ratio of active organisms in ASIM version of ASM\#2

$=0.90 \mathrm{mgTSS} / \mathrm{mgCOD}$ (Gujer, 1993)

$\mathrm{i}_{\text {TSSXI }}=$ TSS to COD ratio of unbiodegradable particulate organics in ASIM version of ASM\#2 $=0.75 \mathrm{mgTSS} /$ mgCOD (Gujer, 1993)

$\mathrm{i}_{\text {TSSXS }}=$ TSS to COD ratio of biodegradable particulate substrate in ASIM version of ASM\#2 $=0.75 \mathrm{mgTSS} /$ mgCOD (Gujer, 1993)

$\mathrm{MS}_{\mathrm{ti}}=$ COD mass load on reactor $(\mathrm{kgCOD} / \mathrm{d})=\mathrm{Q}_{\mathrm{i}} \mathrm{S}_{\mathrm{ti}}$

$\mathrm{MX}_{\mathrm{Io}} \quad=$ mass of ISS in reactor (kgTSS)

$\mathrm{MX}_{\mathrm{t}} \quad=$ mass of TSS in reactor (kgTSS)

$\mathrm{MX}_{\mathrm{v}} \quad=$ VSS mass in reactor (kgVSS)

$\mathrm{Q}_{\mathrm{i}} \quad=$ average dry weather flow (ADWF, M / $/ \mathrm{d}$ )

$\mathrm{R}_{\mathrm{hn}} \quad=$ nominal hydraulic retention time (hours)

$\mathrm{R}_{\mathrm{s}} \quad=$ system sludge age (days)

$\mathrm{S}_{\mathrm{ti}} \quad=$ flow weighted average influent COD concentration entering biological reactor $(\mathrm{mgCOD} / \ell)$

$\mathrm{X}_{\mathrm{Io}} \quad=$ ISS concentration in biological reactor $(\mathrm{mgISS} / \ell)$

$\mathrm{X}_{\mathrm{Ioi}} \quad=$ influent ISS concentration entering biological reactor (mgISS/ $\ell$ )

$\mathrm{X}_{\mathrm{v}}=$ measured or calculated VSS concentration in the reactor $(\mathrm{mgVSS} / \ell)$

$\mathrm{Y}_{\mathrm{H}}, \mathrm{Y}_{\mathrm{G}}=$ yield coefficient for OHOs and PAOs $=0.45 \mathrm{mgVSS} /$ mgCOD $\theta_{\mathrm{b}}=$ temperature sensitivity coefficient for endogenous respiration $=1.029$

$3.286=\mathrm{ISS} / \mathrm{P}$ ratio of polyphosphate

$\%=$ Percentage of influent readily biodegradable COD taken up by PAOs

\section{Introduction}

Reliable predictive models for the organic (volatile) suspended solids (VSS) concentration in activated sludge (AS) system reactors have been developed over the past two decades, e.g. the steady state design model (Ekama et al., 1993; WRC, 1984) and the IWA activated sludge simulation model (ASM)1 (Henze et al., 1987) for fully aerobic (FA) and anoxic-aerobic nitrification-denitrification (ND) systems, and the equivalent steady state design model (Wentzel et al., 1990) and IWA ASM2 (Henze et al., 1995) and 2d (Henze et al., 1999) for anaerobic-anoxic-aerobic ND biological excess phosphorus removal (BEPR) systems. The steady state models are largely stoichiometric materials mass balance based models, that serve as aids for the selection of optimum design parameters for activated sludge systems with measured (or assumed) influent wastewater flows and material concentrations as inputs. Additionally, the simulation models are based on biological transformation kinetic processes and also require, as input, the system design parameters (reactor volumes, recycle flows etc.). In contrast to the organic models above, predictive models for the reactor inorganic suspended solids (ISS), and hence the total suspended solids (TSS $=$ VSS + ISS) concentrations have not received the same attention or general acceptance. Reasonably accurate estimates of the TSS concentration are important for the design and operation of the down-stream unit operations such as secondary settling tanks and sludge treatment systems.

In this paper, predictive models for the ISS concentration in the activated sludge reactor are reviewed and a new model is presented. This model is based on the ISS concentration measured in the influent wastewater and uptake of inorganic dissolved solids (IDS) by the biomass in the reactor. This model is evaluated against experimental data collected from 48 FA, ND and NDBEPR systems operated in the UCT Water Research Laboratory in 21 experimental investigations over 15 years.

\section{Existing ISS and TSS models}

\section{Fully aerobic and anoxic aerobic systems}

In the steady state design models and the original ASM1 for FA and ND systems, a fundamentally based predictive model for the accumulation of the inorganic suspended solids (ISS) in the reactor is not included. The total suspended solids (TSS), which is the sum of the VSS and ISS concentrations, is therefore calculated empirically from an assumed VSS/TSS ratio $\left(\mathrm{f}_{\mathrm{i}}\right)$. This ratio is estimated from historical experience of its value for the particular kind of wastewater and activated sludge system under consideration, and can vary from 0.70 to 0.90 . Once selected it has generally been assumed to remain constant with sludge age (WRC, 1984).

When coding ASM1 into ASIM (Version 2.2), Gujer (1993) included TSS as a non-conservative compound (Gujer and Lawson, 1995), calculated from stoichiometric TSS/COD ratios for the individual mixed liquor organic components; for active biomass $\mathrm{i}_{\text {TSSXBM }}=0.9 \mathrm{mgTSS} / \mathrm{mgCOD}$, for unbiodegradable (inert) organic mass, either from the influent or generated through death-regeneration (endogenous residue), $\mathrm{i}_{\text {TSSXI }}=0.75 \mathrm{mgTSS} / \mathrm{mgCOD}$ and for 


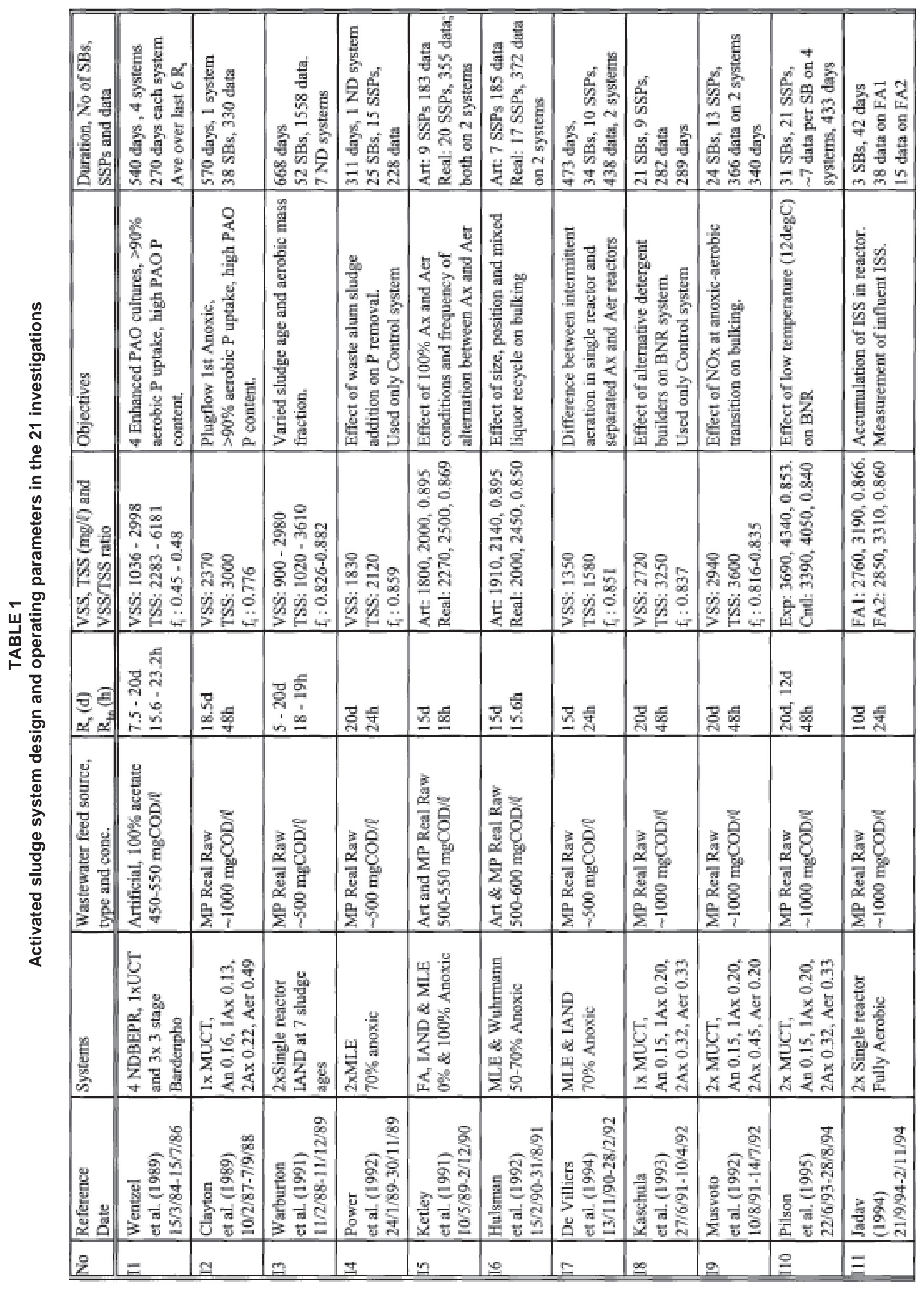




\begin{tabular}{|c|c|c|c|c|c|c|c|c|c|c|c|}
\hline 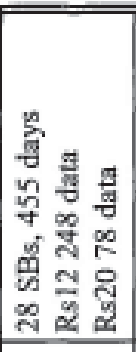 & 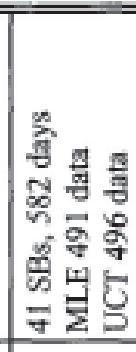 & 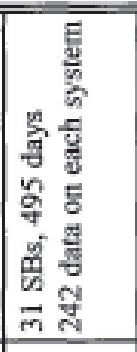 & 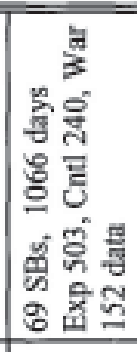 & 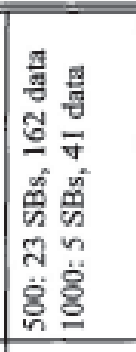 & 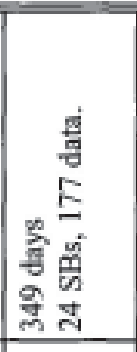 & 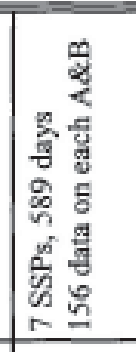 & 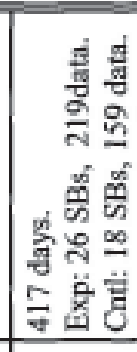 & 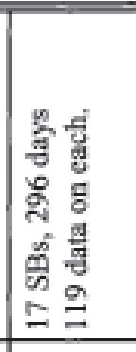 & 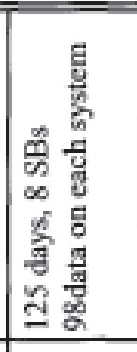 & 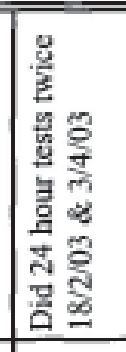 & 8 \\
\hline 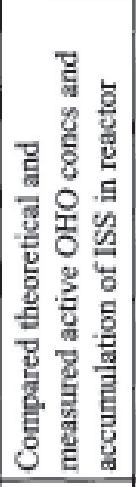 & 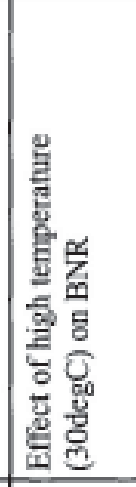 & 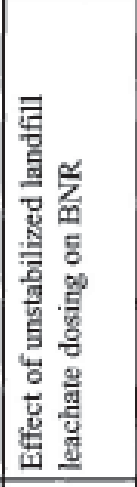 & 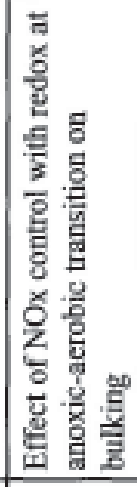 & 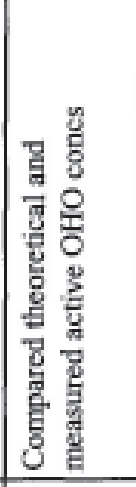 & 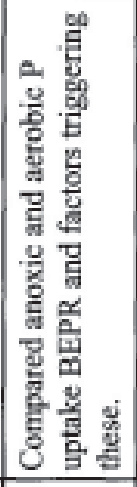 & 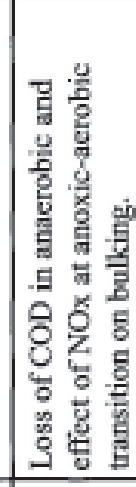 & 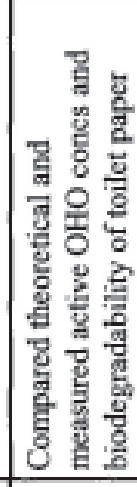 & 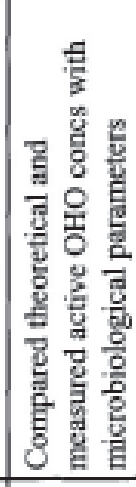 & 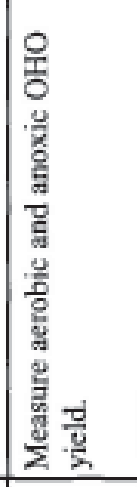 & 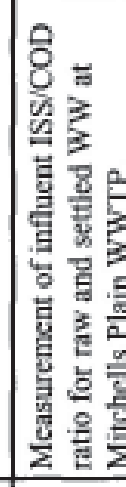 & 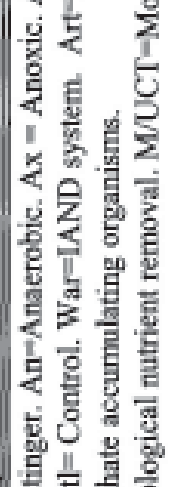 \\
\hline 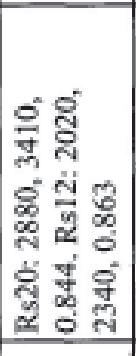 & 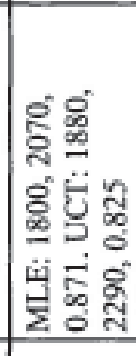 & 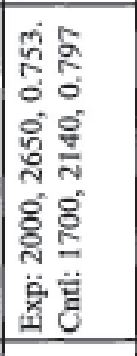 & 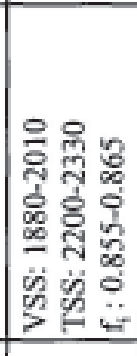 & 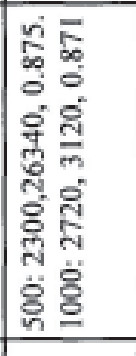 & 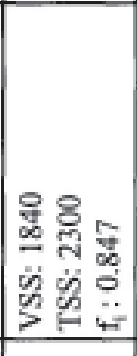 & 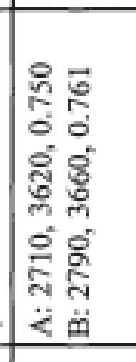 & 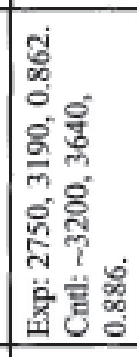 & 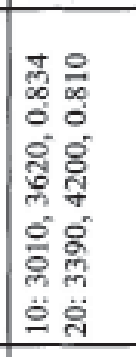 & 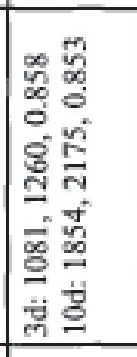 & 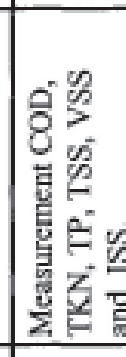 & \\
\hline 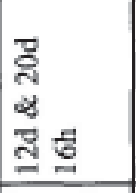 & 䞶表 & 焉胥 & 点胥 & 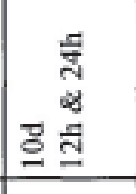 & 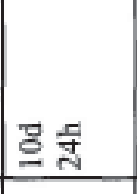 & 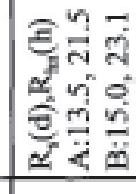 & 邑乐乐 & 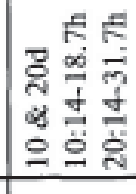 & 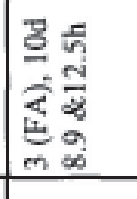 & & \\
\hline छ. & 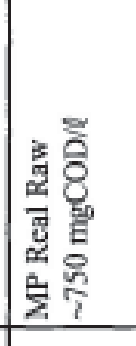 & 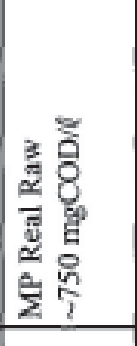 & 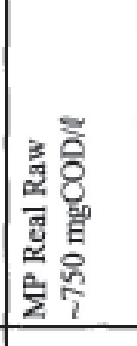 & 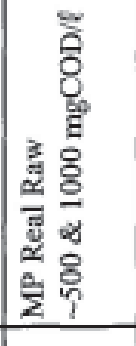 & 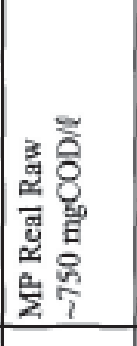 & 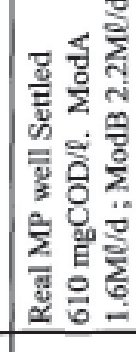 & 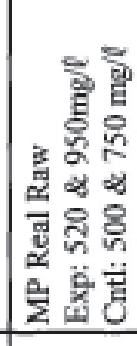 & 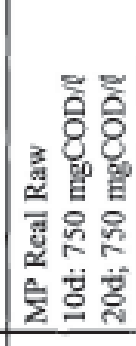 & 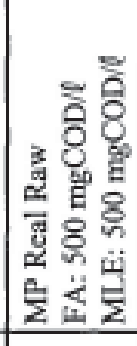 & $\frac{\bar{z}}{z}$ & \\
\hline & 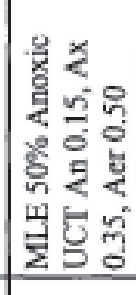 & 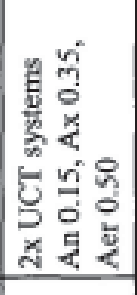 & 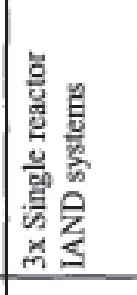 & 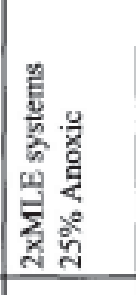 & 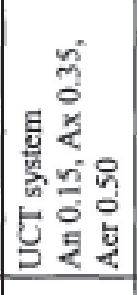 & 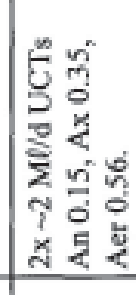 & 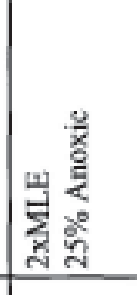 & 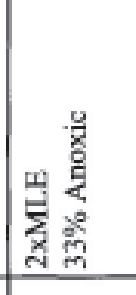 & 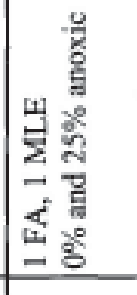 & & \\
\hline 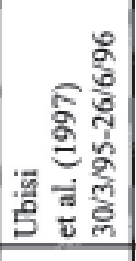 & 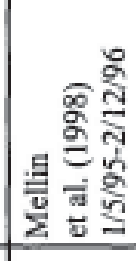 & 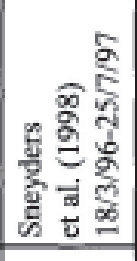 & 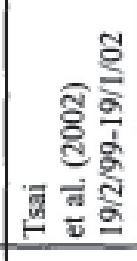 & 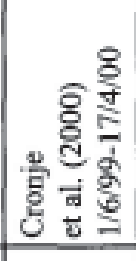 & to & 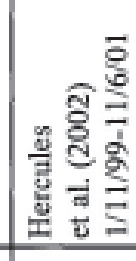 & 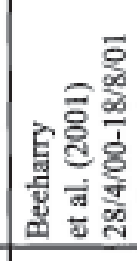 & 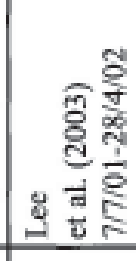 & 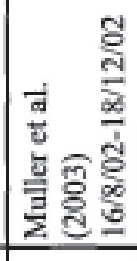 & 量 & \\
\hline & $\underline{m}$ & $\Xi$ & $\underline{n}$ & 16 & & 5 & 1 & . & $\overline{\mathrm{a}}$ & $1=$ & \\
\hline
\end{tabular}


slowly biodegradable particulate substrate, $\mathrm{i}_{\text {TSSXS }}=0.75 \mathrm{mgTSS} /$ $\mathrm{mgCOD}$. These ratios are equivalent to 0.332 and $0.11 \mathrm{mgISS} /$ $\mathrm{mgVSS}$ respectively for a COD/VSS ratio of $1.48 \mathrm{mgCOD} / \mathrm{mgVSS}$. Additionally in the coded model, inorganics (ISS) present in the influent add directly to the reactor TSS. With the ASIM default inorganics present in the influent $(0.117 \mathrm{mgISS} / \mathrm{mgCOD}$, Gujer, 1993), the predicted VSS/TSS ratios of the mixed liquor are around 0.60 and $0.55 \mathrm{mgVSS} / \mathrm{mgTSS}$ for sludge ages of 4 and $30 \mathrm{~d}$ respectively; with zero influent inorganics, the VSS/TSS ratios are 0.80 and 0.85 respectively. Clearly in this model, the predicted mixed liquor inorganics (ISS) concentration is very sensitive to the influent inorganics concentration, but this sensitivity may be artificial because the influent ISS/COD ratio $\left(\mathrm{X}_{\mathrm{Ioi}} / \mathrm{S}_{\mathrm{ti}}\right)$ of 0.117 is very high compared with the raw wastewater values measured on the source wastewater (Mitchells Plain wastewater treatment plant (WWTP) for the 48 experimental systems discussed in this paper, i.e. $0.041-0.050 \mathrm{mgISS} / \mathrm{mgCOD}$.

In modelling experimentally determined ISS concentrations in activated sludge mixed liquor (Investigation I12 - see Table 1), Wentzel et al. (2002) evaluated a number of approaches based on either direct incorporation of influent inorganics (particulate only or total including dissolved solids) or stoichiometric incorporation of inorganics into the organic mixed liquor fractions in addition to direct incorporation of influent inorganics (particulate only or total including dissolved solids). They concluded that the latter approach, which is similar to that of Gujer (1993), provided predictions that best correlated with the experimental observations. With this approach, active biomass and endogenous residue were estimated to contain $\left(f_{B}\right) 0.17 \mathrm{mgISS} / \mathrm{mgVSS}$, while the influent unbiodegradable organics were estimated to contain no inorganics (in contrast to Gujer, 1993); additionally, either $20 \%$ of the influent inorganic particulate (IPS = ISS) or $1.7 \%$ of the total inorganic solids (TIS = ISS + TDS) respectively were entrapped in the mixed liquor. A reasonably close correlation between predicted and measured reactor ISS concentrations was obtained for the ND systems at 12 and 20 ds sludge age. The influent ISS/COD ratio measured by Ubisi et al. (1997) (I12) was $0.093 \mathrm{mgISS} / \mathrm{mgCOD}$, more than twice the ratio measured on the source wastewater at the WWTP by a different method (see below).

\section{Nitrification denitrification biological excess $\mathbf{P}$ removal (NDBEPR) systems}

When modelling ISS and TSS concentrations in NDBEPR systems, due cognizance must be given to the increased intracellular accumulation of inorganic dissolved solids into the phosphate accumulating organisms (PAOs) as polyphosphate and associated counter ions. In the steady state design model for NDBEPR (Wentzel et al., 1990), this increased ISS accumulation is recognised; the reactor TSS concentration is calculated from a constant VSS/TSS ratio of $0.46 \mathrm{mgVSS} / \mathrm{mgTSS}$ for active PAOs and their associated endogenous residue, whereas the rest of the sludge is based on the empirical ratio between $0.75-0.85 \mathrm{mgVSS} / \mathrm{mgTSS}$ derived for ND activated sludge, which includes accumulated influent ISS and remains constant with sludge age. Again, the 0.46 ratio for the PAOs and the selected ratio for the rest of the sludge are assumed to remain constant with sludge age (Wentzel et al. 1990).

In ASM2 and 2d, the principles developed by Gujer above are applied, but additionally the accumulation of inorganics due to polyphosphate and counter ion accumulation in PAOs is included at $3.23 \mathrm{mgISS} / \mathrm{mgP}$.

\section{Model development}

The concept of mixed liquor organic material (VSS) containing inorganic suspended solids (ISS) as implied above by the mgTSS/ mgCOD ratios, may be difficult to grasp. Its not clear how Gujer (1993) visualised this, but in this paper the ISS content of the organics is not visualised as actual inorganics in the VSS itself as it exists in the reactor, but rather as inorganics that are formed in the test procedure. When the mixed liquor organics are in the activated sludge reactor, in particular the active biomass, they include intracellular and/or bound water, which contains dissolved solids. When the organics are dried in the TSS test procedure, these dissolved solids precipitate to form ISS. It is mainly for this conceptual reason that in this paper, only active biomass is accepted to have an ISS/VSS ratio; the unbiodegradable organic components of the mixed liquor clearly cannot contain intracellular water and the bound water is accepted to be negligible.

Experimental data measured in the Water Research Laboratory at the University of Cape Town (UCT) over the past 15 years form the basis for the model development. Altogether 21 investigations were considered, some of which ran concurrently (Table 1). In these investigations, artificial or real wastewater was fed to $30 \mathrm{FA}$ or ND and 18 NDBEPR systems operated over a range of sludge ages ( 3 to 20d) and nominal hydraulic retention times 8.9 to $48 \mathrm{~h}$ (Table 1).

\section{Conceptual model}

Conceptually the reactor ISS concentration predictive model is based on the following principles:

- ISS in the influent $\left(\mathrm{X}_{\mathrm{Ioi}}, \mathrm{mgISS} / \ell\right)$ accumulates in the reactor $\left(\mathrm{X}_{\mathrm{IO}}\right)$. From a mass balance, this accumulation is proportional to the sludge age $\left(\mathrm{R}_{\mathrm{s}}\right)$ and inversely proportional to the nominal hydraulic retention time $\left(\mathrm{R}_{\mathrm{hn}}\right)$, i.e.

$$
X_{I o}=X_{I o t} R / R_{h n} \operatorname{mgISS} / \ell
$$

This is in agreement with proposals of Gujer (1993) reviewed above.

- Precipitation of minerals in the biological reactor, unless stimulated by chemical dosing, and dissolution of influent ISS, are considered negligible.

- In contrast to the inorganic models of ASM2, 2d and Gujer (1993), but in agreement with Wentzel et al. (2002), slowly biodegradable particulate substrate does not contain an inorganic component.

- The ordinary heterotrophic organisms (OHOs) and the phosphate accumulating organisms (PAOs) take up intra-cellular inorganic dissolved solids (IDS) as part of the biomass which, when sludge samples are dried and incinerated in the TSS-VSS test procedure, precipitate as inorganic solids. In so far as solids (organic and inorganic) accumulation in the reactor is concerned, the autotrophic nitrifying organisms (ANOs) are ignored because their relative contribution is very small $(<2 \%)$.

- Additionally, the PAOs take up inorganic dissolved solids (IDS) and store it as polyphosphate with associated counter ions, in conformity with ASM2 and 2d.

- Although in ASM2, 2d, Gujer (1993) and Wentzel et al. (2002), inorganics are included in the endogenous residue fraction, Wentzel et al. (2002) noted that there is no information in the literature on the validity of this assumption. In the model developed here, it is assumed that there are no inorganics 
associated with unbiodegradable particulate organics, which includes endogenous residue. This assumption will be evaluated in the model application.

Following the above, the combined measured ISS in the reactor is given by:

$$
X_{I o}=X_{I o i} R_{s} R_{h n}+X_{v}\left(f_{\text {iOHO }} f_{\text {avOHO }}+f_{i P A O} f_{a v P A O}\right) \mathrm{mgISS} / \ell
$$

where:

$$
\begin{aligned}
\mathrm{X}_{\mathrm{v}}= & \begin{array}{l}
\text { measured or calculated VSS concentration in } \\
\text { the reactor }(\mathrm{mgVSS} / \ell)
\end{array} \\
\mathrm{f}_{\text {iOHO }}, \mathrm{f}_{\mathrm{iPAO}}= & \text { inorganic material content of the OHOs and } \\
& \text { PAOs respectively (mgISS/mgVSS) } \\
\mathrm{f}_{\text {avOHO }}, \mathrm{f}_{\text {avPAO }}= & \text { fraction of the VSS concentration which is } \\
& \text { OHOs and PAOs respectively, and } \\
= & \mathrm{f}_{\text {iPAOBM }}+\mathrm{f}_{\text {iPAOPP }} \\
\mathrm{f}_{\text {iPAO }}= & \text { inorganic material content of the PAO active } \\
\text { where: } & \text { biomass (mgISS/mgVSS) } \\
\mathrm{f}_{\text {iPAOBM }}= & \text { inorganic material content of the PAO } \\
& \text { polyphosphate }(\text { mgISS/mgVSS) }
\end{aligned}
$$

The OHO and PAO fractions of the VSS $\left(f_{\text {avOHO }}, f_{\text {avPAO }}\right)$ are defined by, and can be calculated with the existing AS models. The one used in this ISS model development is the steady state BEPR model of Wentzel et al. (1990), which for zero anaerobic mass fraction and influent SCFA COD (i.e. no BEPR) is identical to the steady state ND AS model of Ekama et al. (1983) and WRC (1984). Although developed earlier, these steady state models are essentially a subset of the dynamic simulation models which can be calibrated to give similar results for the same input conditions. The ISS model developed here therefore can be included relatively simply in these dynamic simulation models and the numerical values determined for $\mathrm{f}_{\text {iOHO }}$ and $\mathrm{f}_{\mathrm{iPAO}}$ are consistent for these models.

In the ISS model developed here (Eq 2), there are three unknown parameters which need to be determined, i.e. the influent ISS concentration $\left(\mathrm{X}_{\mathrm{Io}}\right)$, which may be directly measured, and the inorganic contents of the OHOs and PAOs $\left(f_{\mathrm{iOHO}}\right.$ and $\left.f_{\mathrm{iPAO}}\right)$, which cannot be measured directly, only calculated indirectly by matching measured and model predicted reactor ISS and VSS concentrations. Because in the 21 investigations (I1 to I21), the influent ISS concentration generally was not measured, except in I11, I12, I18 and in two $24 \mathrm{~h}$ tests at the WWTP (I22, see Table 1), the values of all three parameters were determined from the results of the 48 experimental systems.

\section{Experimental investigation}

Details of the 21 experimental investigations are listed in Table 1 . For the 42 systems fed real wastewater, Mitchells Plain unsettled (raw) wastewater was collected at the treatment plant in $2 \mathrm{~m}^{3}$ batches, trucked to the laboratory, macerated and stored in $400 \ell$ stainless steel tanks in a $4^{\circ} \mathrm{C}$ cold room. Daily, the wastewater volume required for the activated sludge systems was, after thorough mixing, drawn from the $400 \ell$ tanks, strained through $1 \mathrm{~mm}$ mesh to avoid pipe blockages, diluted with tap water to the target influent COD concentration for the AS system, and poured into the system's feed drum. The collected sewage batches were used over a period of 2 to 3 weeks. During this time, the systems were tested at least every second day, but usually more frequently, for influent, reactor(s) and effluent unfiltered and filtered chemical oxygen demand (COD), total Kjeldahl nitrogen (TKN), free and saline ammonia (FSA), nitrate, nitrite, total phosphorus (TP), orthophosphate (OP), VSS and TSS concentrations, and oxygen utilisation rate (OUR) and diluted sludge volume index (DSVI) in the aerobic reactor. These measurements, which are listed in the reports of the investigations (Table 1), were averaged over the sewage batches (SB) or longer steady state periods (SSPs) when the influent concentrations over several consecutive sewage batches did not change significantly and system operating conditions were not changed.

\section{Model application}

In application of the model (Eq. 2) to the various systems, the following were accepted:

- Systems fed artificial wastewater received zero or very low influent ISS $\left(\mathrm{X}_{\mathrm{Ioi}}=0\right)$. The ISS measured in the reactor is therefore predominantly the ISS content of the OHOs and/or PAOs. The 6 systems (2 ND and 4 NDBEPR) fed artificial wastewater formed the starting point for determining the initial estimates for the OHO and PAO ISS contents ( $\mathrm{f}_{\mathrm{iOHO}}$ and $\mathrm{f}_{\mathrm{iPAO}}$ ).

- Because the influent ISS concentrations $\left(\mathrm{X}_{\mathrm{Ioi}}\right)$ were not measured, except in I11, I12 and I18, this concentration was calculated with Eq. (2) from the measured reactor ISS concentration $\left(\mathrm{X}_{\mathrm{IO}}\right)$ and the initial estimates of $\mathrm{f}_{\mathrm{iOHO}}$ and $\mathrm{f}_{\mathrm{iPAO}}$ for each SB or SSP and each system in each investigation. Because different influent COD concentrations were fed to the different systems by diluting the collected wastewater with tap water to a target feed COD concentration, this calculated influent ISS concentration was expressed as a ratio of the feed COD concentration $\left(\mathrm{S}_{\mathrm{ti}}\right)$ i.e. $\mathrm{X}_{\mathrm{Ioi}} / \mathrm{S}_{\mathrm{ti}} \mathrm{mgISS} / \mathrm{mgCOD}$, to make the influent ISS comparable between systems and investigations. Consistency of the influent $\mathrm{X}_{\mathrm{Ioi}} / \mathrm{S}_{\mathrm{ti}}$ ratio over a range of sludge ages and retention times in the same investigation and between investigations allowed refinement of the initial $\mathrm{f}_{\mathrm{iOHо}}$ estimate from the artificial wastewater systems.

\section{Calculation method}

In more detail, for each SB or SSP of a system in an investigation, the $\mathrm{OHO}$ and/or PAO active fractions $\left(\mathrm{f}_{\text {avOHO }}, \mathrm{f}_{\text {avPAO }}\right)$ for FA, ND or NDBEPR systems were calculated iteratively with the aid of the steady state BEPR model of Wentzel et al. (1990). The measured values for the influent $C O D, R B C O D$ fraction and unbiodegradable soluble COD fraction $\left(\mathrm{f}_{\mathrm{S}^{\prime} \text { us }}=\right.$ filtered effluent $\mathrm{COD} / \mathrm{S}_{\mathrm{ti}}$ ) were input to the model together with the system constraints, and the particulate unbiodegradable COD fraction $\left(\mathrm{f}_{S^{\prime} \text { up }}\right.$ ) was varied until the calculated system VSS mass, comprising active and endogenous PAO and $\mathrm{OHO}$ components and unbiodegradable particulate VSS from the influent, matched the measured values. For the NDBEPR systems, when the correct $\mathrm{f}_{S^{\prime} \text { up }}$ had been found, the calculated $\mathrm{P}$ removal was matched to that measured by decreasing the PAO P content $\left(\mathrm{f}_{\mathrm{XBGP}}\right)$ from the standard value of $0.38 \mathrm{mgP} / \mathrm{mgPAOVSS}$ to a lower value (Ekama and Wentzel, 1999). Generally, when the $\mathrm{P}$ uptake was predominantly aerobic ( $>90 \%$ of total $\mathrm{P}$ uptake), the calculated $\mathrm{f}_{\mathrm{XBGP}}$ was close to the $0.38 \mathrm{mgP} / \mathrm{mgPAOVSS}$ value for the enhanced PAO cultures of Wentzel et al. (1989a) (e.g. I1, I2 and I14). However, when significant anoxic P uptake took place (>20\%), the calculated $\mathrm{f}_{\mathrm{XBGP}}$ was lower than $0.38 \mathrm{mgP} / \mathrm{mgPAOVSS}$ (i.e. I8, I9, I10, I13, I17 and I18). For the FA and ND systems, the anaerobic mass fraction $\left(f_{\mathrm{xa}}\right)$ and influent RBCOD fraction $\left(\mathrm{f}_{\mathrm{Sb}^{\prime} \mathrm{s}}\right)$ were set to zero, which in the model stops PAOs, and their associated endogenous VSS from forming in the system, with the 
result that $\mathrm{f}_{\text {avPAO }}=0$. For the enhanced PAO cultures of Wentzel et al. (1989a) (I1), $\mathrm{f}_{\mathrm{Sb}^{\prime} \mathrm{s}}$ was set to 1.0 because all the influent COD was in SCFA form, which in the model, stops OHOs and their associated endogenous VSS, from forming in the system, with the result that $\mathrm{f}_{\text {av } \mathrm{OHO}}=0$.

With the $\mathrm{f}_{\text {avOHO }}$ and $\mathrm{f}_{\text {avPAO }}$ known for each SB or SSP of a system in an investigation, Eq. (2) was used with the measured reactor ISS concentration $\left(\mathrm{X}_{\mathrm{IO}}\right)$ and initial estimates for the ISS contents of the OHOs and PAOs ( $f_{\text {iOHO }}$ and $\mathrm{f}_{\mathrm{iPAO}}$ ) to calculate the influent ISS concentration $\left(\mathrm{X}_{\mathrm{Io}}\right)$ for each SB or SSP of a system in an investigation. For each system in an investigation, the weighted mean $\mathrm{X}_{\mathrm{Ioi}}$ values were determined by multiplying the SB or SSP average $X_{\text {Ioi }}$ values by the number of tests in the SB or SSP, adding these over the whole investigation and dividing by the total number of tests on the system in the investigation. For investigations with more than one system, a weighted investigation mean $\mathrm{X}_{\mathrm{Ioi}}$ mean was calculated from the weighted system $\mathrm{X}_{\mathrm{Ioi}}$ means. The investigation weighted mean $\mathrm{X}_{\text {Iоi }}$ and selected $\mathrm{f}_{\text {iОНО }}$ and $\mathrm{f}_{\text {iPAO }}$ were then applied in Eq. 2 to the SB or SSP average data to determine the calculated reactor ISS concentrations $\left(\mathrm{X}_{\mathrm{Io}}\right)$ for each $\mathrm{SB}$ or SSP, which were then compared with measured SB or SSP ISS concentrations on each system. For those investigations where the influent ISS was not measured, the final $\mathrm{f}_{\mathrm{iOHO}}$ and $\mathrm{f}_{\mathrm{iPAO}}$ values accepted were those that gave the most consistent comparison between calculated and measured reactor ISS concentrations over all the SBs or SSPs of the different systems of an investigation and between investigations. For those investigations where the influent ISS $\left(\mathrm{X}_{\mathrm{Ioi}}\right)$ was measured (i.e. I11, I12 and I18), the $f_{\text {іоно }}$ and $f_{\text {iРАO }}$ values were varied until the calculated weighted mean influent ISS matched that measured for the investigation.

\section{Determination of the ISS content of PAOs $-f_{\text {iPAO }}$}

The four $100 \%$ acetate feed enhanced PAO culture systems of Wentzel et al. (1989a) at 7.5, 10, 10 and $20 \mathrm{~d}$ sludge age, yielded VSS/TSS ratios of $0.45,0.46,0.46$ and $0.48 \mathrm{mgVSS} / \mathrm{TSS}$ respectively. The values seem extra-ordinarily low and indicate very high ISS concentrations in the systems, higher than the VSS concentrations. Wentzel et al. (1989b) state that the reason for these high ISS concentrations is the very high phosphate content of the PAOs $\left(\mathrm{f}_{\mathrm{XBGP}}\right)=0.38 \mathrm{mgP} / \mathrm{mgPAOVSS}$. Accepting a biomass structural $\mathrm{P}$ content $\left(\mathrm{f}_{\mathrm{XBGPBM}}\right)$ of $0.03 \mathrm{mgP} / \mathrm{mgVSS}$ gives an intracellular polyphosphate content $\left(\mathrm{f}_{\mathrm{XBGPP}}\right.$ ) of $0.35 \mathrm{mgP} / \mathrm{mgPAOVSS}$ (i.e. $\mathrm{f}_{\text {XBGPP }}=\mathrm{f}_{\text {XBGP }}-\mathrm{f}_{\text {XBGBM }}$ ). This polyphosphates is charge balanced by cations $\mathrm{Mg}, \mathrm{Ca}$ and $\mathrm{K}$ but mainly $\mathrm{Mg}$, all of which were measured as ISS in the test procedure.

Applying Eq. (2) with both $\mathrm{X}_{\mathrm{Ioi}}$ and $\mathrm{f}_{\text {avОНО }}=0$ to the enhanced PAO cultures yields a total ISS content of PAOs $\left(f_{\text {iPAO }}\right)$ of 1.30 $\mathrm{mgISS} / \mathrm{mgPAOVSS}$. This constant $\mathrm{f}_{\mathrm{iPAO}}$ value in the PAO steadystate BEPR model of Wentzel et al. (1990) predicted the observed increasing VSS/TSS ratio with sludge age very accurately (Fig. 1). The predicted and measured reactor ISS and VSS concentrations and masses are compared in Figs. 1 and 2 respectively. These correlations also are very good. The consistency with which a constant $\mathrm{f}_{\text {iPAO }}$ predicts the observed changes in VSS/TSS ratio with sludge age gives credibility to the approach of Eq. (2) (with both $\mathrm{f}_{\text {iOHO }}$ and $\mathrm{X}_{\text {Ioi }}=0$ ). This $\mathrm{f}_{\text {iPAO }}=1.30$ did not require to be revised in the subsequent ISS model development for real wastewater, but did require modification to take into account reduced polyphosphate storage with anoxic P uptake BEPR (see below).

The P uptake in the enhanced PAO cultures was predominantly aerobic $(>90 \%)$ and the P content of the PAOs $\left(\mathrm{f}_{\mathrm{XBGP}}\right)$ was 0.38 $\mathrm{mgP} / \mathrm{mgPAOVSS}$. Accepting a PAO cell structural P content

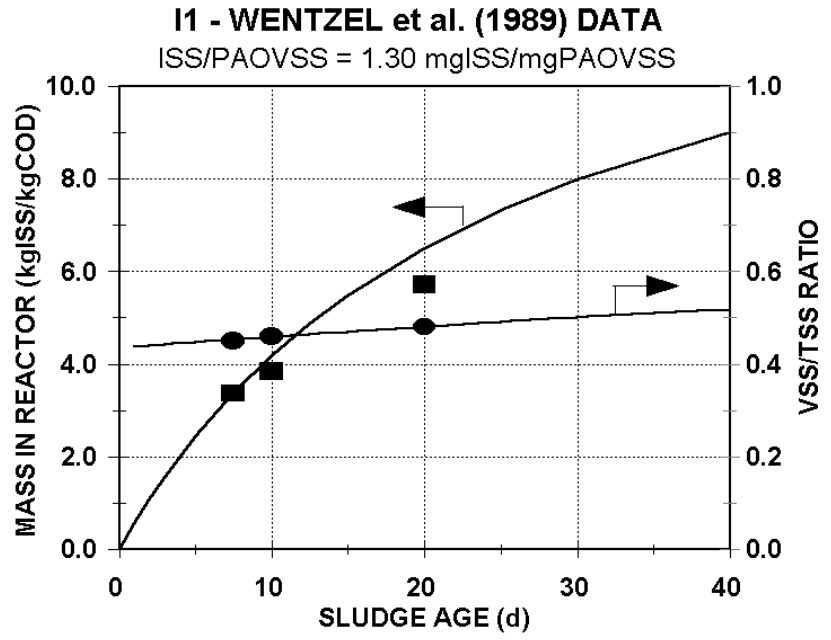

Figure 1

Measured reactor ISS mass in $\mathrm{kg} / \mathrm{SS} / \mathrm{kgCOD}$ load (घ) and VSS/ TSS ratio $(\bullet)$ and predicted (lines) vs. sludge age for the four acetate fed enhanced PAO cuture systems of Wentzel et al. (1989) (I1) accepting PAO ISS content $f_{\text {iPAO }}=1.30 \mathrm{mg} / \mathrm{SS} /$ mgVSS (>90\% aerobic $P$ uptake BEPR)

11 - Wentzel et al. (1989) DATA ISS/PAOVSS $=1.30 \mathrm{mgISS} / \mathrm{mgPAOVSS}$

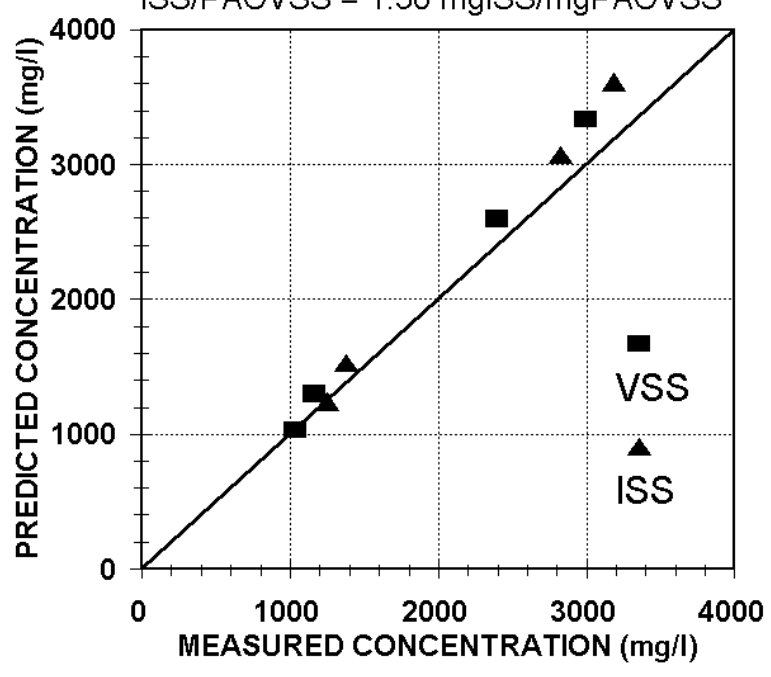

Figure 2

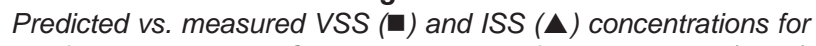
the four enhanced PAO culture systems of Wentzel et al. (1989) (I1) at sludge ages 7.5, 10, 10 and $20 \mathrm{~d}$ for ISS content of PAOs $\left(f_{i P A O}\right)=1.3 \mathrm{mg} / \mathrm{SS} / \mathrm{mg}$ PAOVSS

$\left(\mathrm{f}_{\text {XBGPBM }}\right)$ of $0.03 \mathrm{mgP} / \mathrm{mgVSS}$ and a polyphosphate content $\left(\mathrm{f}_{\text {XBGPP }}\right)$ of $0.35 \mathrm{mgP} / \mathrm{mgVSS}$, theoretical ISS values for the polyphosphate $\left(\mathrm{f}_{\mathrm{iPAOPP}}\right)$ and PAO active biomass $\left(\mathrm{f}_{\mathrm{iPAOBM}}\right)$ can be calculated. With the average molar ratio of polyphosphate cations from Fukase et al. (1982), Arvin and Kristensen (1985), Comeau et al. (1985) and Wentzel et al. (1989b) of $\mathrm{Mg}: \mathrm{K}: \mathrm{Ca}: \mathrm{P}=0.275: 0.295: 0.05: 1$, and recognising that $\mathrm{P}$ in polyphosphate exists as $\mathrm{PO}_{3}$, then the molecular mass of polyphosphate is $98.8 \mathrm{mg} / \mathrm{mmol}$. With polyphosphate entirely inorganic, the theoretical ISS/P ratio for polyphosphate is $3.19 \mathrm{mgISS} / \mathrm{mgP}$, closely equal to the value of $3.23 \mathrm{mgISS} / \mathrm{mgP}$ adopted in ASM2 and 2d. A $\mathrm{f}_{\text {XвGPP }}=0.35 \mathrm{mgpolyP} / \mathrm{mgPAOVSS}$ gives $\mathrm{f}_{\text {iPAOPP }}=1.12 \mathrm{mgISS} / \mathrm{mgPAOVSS}$ for the polyphosphate. 
Accepting that the PAO cell non-polyphosphate inorganic content $\mathrm{f}_{\text {iPAOBM }}$ is equal to the OHO inorganic content $\left(\mathrm{f}_{\mathrm{iOHO}}\right)$ of $0.15 \mathrm{mgISS} /$ mgVSS (see later), then the total PAO inorganic content $\left(\mathrm{f}_{\mathrm{iPAO}}\right)=$ $1.12+0.15=1.27 \mathrm{mgISS} / \mathrm{mgPAOVSS}$. This very closely matches the value of 1.30 determined above in application of the model to the enhanced PAO culture data, and lends further support to this value.

\section{Determination of the ISS content of OHOs - $f_{\text {іоно }}$}

The $\mathrm{OHO}$ active biomass in AS systems contains ISS as indicated by work on pure OHO cultures (e.g. Gaudy and Gaudy, 1980). A range of OHO ISS content $\left(\mathrm{f}_{\text {іоно }}\right)$ values are reported in the literature, from 0.05 to $0.25 \mathrm{mgISS} / \mathrm{mgOHOVSS}$. Five investigations with 15 fully aerobic (FA) and nitrification-denitrification (ND) systems (i.e. no PAOs) listed in Table 1 were selected as the basis for determining the $\mathrm{f}_{\text {iОНО, }}$, viz. I3, I5, I6, I11 and I12. These systems were selected because they were operated over a range of sludge ages (I3; 5 to 20d); were fed artificial wastewater, i.e. zero or low $\mathrm{X}_{\mathrm{Ioi}}$; or included measurement of influent total dissolved (TDS) and suspended (TSS) solids, each separated into organics (VDS, VSS) and inorganics (IDS, ISS), i.e. I11 and I12.

For the 2 artificial wastewater fed ND systems of I5 and I6, it was expected that the influent ISS would be zero or at least very low. With $\mathrm{X}_{\mathrm{Ioi}}=0, \mathrm{f}_{\mathrm{iOHO}}$ needed to be 0.276 and $0.265 \mathrm{mgISS} /$ mgOHOVSS respectively to account for the measured ISS in the reactor. This was outside the literature range and considered too high, which was confirmed with the data from the real wastewater investigations I3, I5, I6 and I1 1, where such high $\mathrm{f}_{\text {іоно }}$ values led to negative influent ISS concentrations, especially for the I3 short sludge age systems.

The SB or SSP calculated vs. measured reactor ISS concentrations $\left(\mathrm{X}_{\mathrm{to}}\right)$ and VSS/TSS ratios for the 7 real wastewater systems of I 3 for $\mathrm{f}_{\text {іоно }}=0.276$ and the corresponding investigation weighted mean influent ISS/COD ratio $=0.0170$ are shown in Figs. 3 and 4 respectively. The reactor ISS (Fig. 3) data correlate poorly and the system mean reactor ISS concentrations at the different sludge ages lie at a much flatter slope than the 1:1 correlation line. The VSS/ TSS ratio data (Fig. 4) also correlate poorly and the system mean ratios at the different sludge ages lie almost perpendicular to the 1:1 correlation line. The calculated system mean influent ISS $\left(\mathrm{X}_{\mathrm{Ioj}}\right)$ for $\mathrm{f}_{\text {iоно }}=0.276$ to account for the measured reactor TSS $\left(\mathrm{X}_{\mathrm{Io}}\right)$ is plotted vs. sludge age in Fig 5. Not only does the calculated $\mathrm{X}_{\mathrm{Ioi}}$ decrease with sludge age, but also -ve values are obtained at the low sludge ages of 5 and $6 \mathrm{~d}$. Moreover, the estimated influent ISS/ COD ratio is too low ( $0.017 \mathrm{mgISS} / \mathrm{mgCOD})$ compared with that measured on the wastewater in the laboratory (i.e. 0.031 in I11) and at the treatment plant (0.041-0.050 in I22, see Table 2). This means that $\mathrm{f}_{\text {іОоо }}=0.276$ is too high and does not correctly account for the changes in measured reactor ISS with sludge age. Curiously, the best correlation between calculated and measured reactor ISS for the 7 systems of $\mathrm{I} 3$ is obtained when $\mathrm{f}_{\text {iOHO }}=0.0$ (Figs. 6 to 8 ), which gives the least variation in influent ISS concentration $\left(\mathrm{X}_{\mathrm{Ioi}}\right)$ with sludge age (Fig. 8); and an investigation weighted mean influent ISS/COD ratio of 0.045 , which is midway between the ratios measured in the two $24 \mathrm{~h}$ tests at the source WWTP (0.04 to 0.05 , Table 2).

In the I11 and I12 investigations with FA and ND systems, influent and effluent TDS and IDS, and TSS and ISS were measured. In I11, the average measured influent ISS/COD ratio $\left(\mathrm{X}_{\mathrm{Ioi}} / \mathrm{S}_{\mathrm{ti}}\right)$ was $0.031 \mathrm{mgISS} / \mathrm{mgCOD}$. At this value, for I1 1 the $\mathrm{f}_{\text {іоно }}$ has to be $0.11 \mathrm{mgISS} / \mathrm{mgOHOVSS}$ to account for the measured reactor ISS. Interestingly, in this investigation, a $46.1 \mathrm{mg} / \ell$ decrease in inor-
13 - WARBURTON et al. (1991) DATA

SLUDGE AGE 5-20d; ISS/OHOVSS $=0.27$

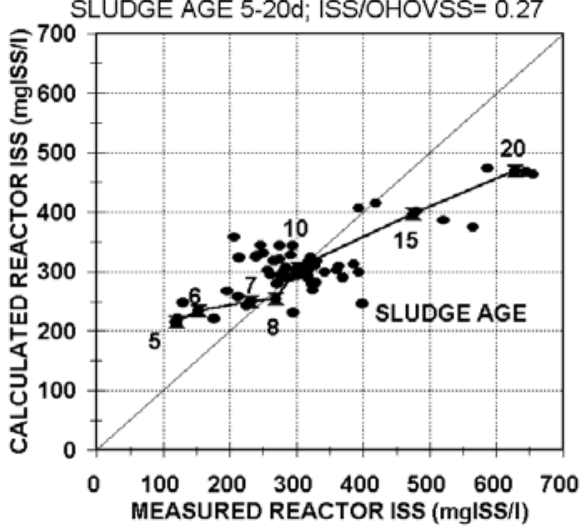

Figure 3

Calculated with $\mathrm{OHO}$ ISS content $f_{\text {іОно }}=0.27 \mathrm{mg} / \mathrm{SS} /$

mgOHOVSS vs. measured sewage batch average $(\bullet)$ and system average (neactor ISS concentration for the seven real WW ND systems of Warburton et al. (1991) (I3) at sludge ages $5,6,7,8,10,15$ and $20 d$

13 - WARBURTON et al. (1991)

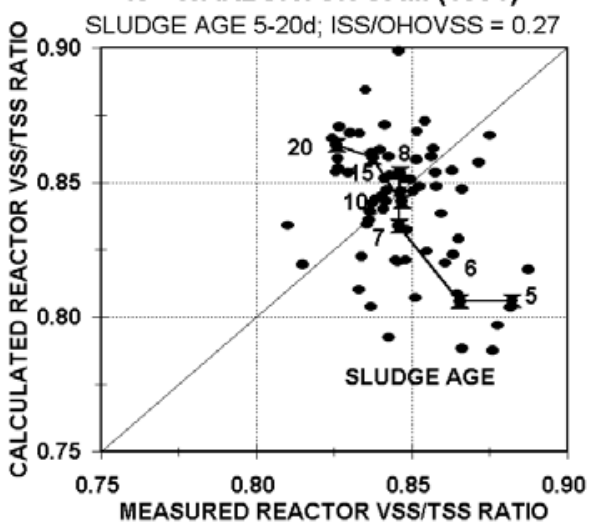

Figure 4

Calculated with OHO ISS content $f_{\text {іОно }}=0.27 \mathrm{mg} / \mathrm{SS} /$ mgOHOVSS vs. measured sewage batch average (•) and system average (neactor VSS/TSS ratio for the seven real WW ND systems of Warburton et al. (1991) (I3) at sludge ages $5,6,7,8,10,15$ and $20 d$.

I3 - WARBURTON et al. (1991) DATA ISS/OHOVSS $=0.27 \mathrm{mgISS} / \mathrm{mgOHOVSS}$

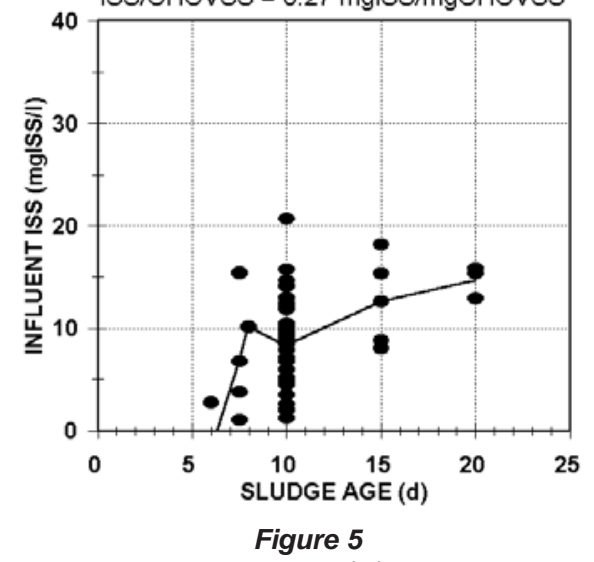

Calculated sewage batch average $(\bullet)$ and system average (( $(\mathbf{}))$ influent ISS concentration vs. sludge age for the seven real WW ND systems of Warburton et al. (1991) (I3) for OHO ISS content $f_{\text {iоно }}=0.27 \mathrm{~g} / \mathrm{SS} / \mathrm{mgOHOVSS}$. 


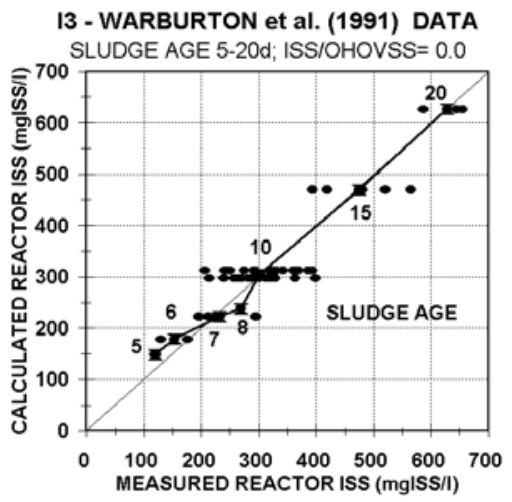

Figure 6

Calculated with $\mathrm{OHO}$ ISS content $f_{\text {іОоО }}=$ $0.0 \mathrm{mg} / \mathrm{SS} / \mathrm{mgOHOVSS}$ vs. measured sewage batch average (•) and system average ( reactor ISS concentration for the seven real WW ND systems of Warburton et al. (1991) (I3) at sludge ages 5, 6, 7, 8, 10, 15 and $20 d$
13 - WARBURTON et al. (1991)

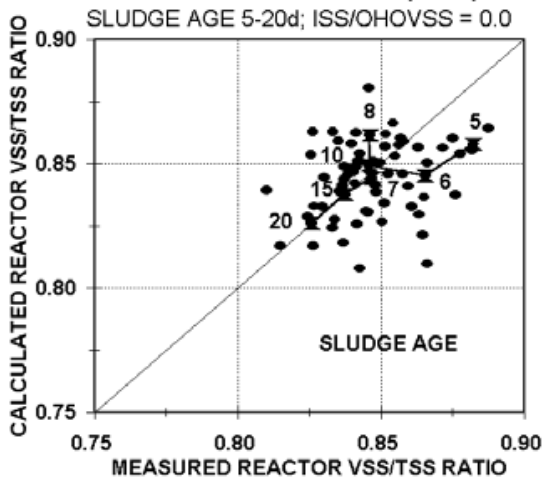

Figure 7

Calculated with OHO ISS content $\mathrm{f}_{\text {іОно }}=$ $0.0 \mathrm{mg} / \mathrm{SS} / \mathrm{mgOHOVSS}$ vs. measured sewage batch average (•) and system average ( reactor VSS/TSS ratio for the seven real WW ND systems of Warburton et al. (1991) (I3) at sludge ages 5, 6, 7, 8, 10, 15 and $20 d$
I3 - WARBURTON et al. (1991) DATA

ISS $/ \mathrm{OHOVSS}=0.0 \mathrm{mgISS} / \mathrm{mgOHOVSS}$

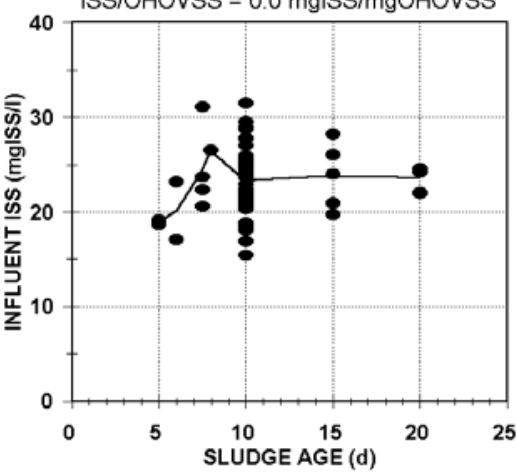

Figure 8

Calculated sewage batch average (•) and system average (influent ISS concentration vs. sludge age for the seven real WW ND systems of Warburton et al. (1991) (I3) for $\mathrm{OHO}$ ISS content $f_{\text {іОно }}=0.0 \mathrm{mg} / \mathrm{SS} /$ mgOHOVSS

\section{TABLE 2}

Mitchells Plain (source) wastewater influent ISS/COD ratios measured at the treatment plant before (raw, I22) and after (settled, I22, I18) primary settling and in the laboratory on the collected raw wastewater (I11 and I12)

\begin{tabular}{|c|c|c|c|c|}
\hline \multicolumn{3}{|c|}{$\begin{array}{l}\text { At the Mitchells Plain wastewater } \\
\text { treatment plant }\end{array}$} & \multicolumn{2}{|c|}{ In the laboratory } \\
\hline Investigation & Raw & Settled & Investigation & Raw \\
\hline $\begin{array}{c}\text { I18 } \\
\text { I22: Test } 1^{\mathrm{b}} \\
\text { I22: Test } 2^{\mathrm{b}}\end{array}$ & $\begin{array}{c}- \\
0.041 \\
0.050\end{array}$ & $\begin{array}{l}0.041 \\
0.039 \\
0.043\end{array}$ & $\begin{array}{l}\mathrm{I} 11^{\mathrm{a}} \\
\mathrm{I} 12^{\mathrm{a}}\end{array}$ & $\begin{array}{c}0.031 \\
0.087-0.096\end{array}$ \\
\hline \multicolumn{5}{|c|}{$\begin{array}{l}\text { a Determined by filtration through Whatman's No } 1 \text { ashless filter } \\
\text { papers of known dry mass, drying at } 105^{\circ} \mathrm{C} \text { for } 24 \mathrm{~h} \text { and incineration } \\
\text { in a crucible of known dry mass at } 600^{\circ} \mathrm{C} \text { for } 20 \mathrm{~min} \\
\text { b Determined by filtration through pretreated glass fibre membranes of } \\
\text { known dry mass, drying at } 105^{\circ} \mathrm{C} \text { for } 24 \mathrm{~h} \text { and incineration at } 600^{\circ} \mathrm{C} \\
\text { for } 20 \text { min. Filter pretreatment comprises incineration at } 600^{\circ} \mathrm{C} \text { for } \\
6 \mathrm{~h} \text { to stabilise its mass before subsequent heating. }\end{array}$} \\
\hline
\end{tabular}

mgISS/mgOHOVSS and endogenous residue also included inorganics. Compared with the influent ISS concentration measured by a different method at the source WWTP (I22 see Table 1), i.e. $0.041 \mathrm{mgISS} / \mathrm{mgCOD}$ (Table 2), it does seem that the influent ISS was measured too high in I12. Measurement of influent ISS is discussed further below.

By trial and error comparison of the calculated and measured reactor ISS concentrations within the systems of an investigation and between investigations and taking cognizance of the measured influent ISS/COD ratio at the source WWTP (I22), it was concluded that $\mathrm{f}_{\text {іоно }}=0.15$ $\mathrm{mgISS} / \mathrm{mgOHOVSS}$ is the best compromise value for the 2 artificial (I5, I6) and 13 real (I3, I5, I6, I11, I12) WW systems of the 5 investigations discussed above. For the 7 systems and $52 \mathrm{SBs}$ of $\mathrm{I} 3$, with $\mathrm{f}_{\text {іоно }}=0.15$ the investigation weighted mean influent ISS/COD ratio of all 7 systems is 0.030 . With these values, the calculated vs. measured reactor ISS and VSS/TSS ratio are shown in Figs. 9 and 10 respectively, and the influent ISS $\left(\mathrm{X}_{\mathrm{Ioi}}\right)$ and reactor VSS/ TSS ratio vs. sludge age in Figs. 11 and 12 respectively. The calculated influent ISS concentration vs. sludge age is reasonably consistent between 16 and $19 \mathrm{mgISS} / \ell\left(\mathrm{X}_{\mathrm{Ioi}} / \mathrm{S}_{\mathrm{ti}}=\right.$ 0.030 to 0.036 ) except for the 5 and $6 \mathrm{~d}$ sludge age, where it is lower. At these short sludge ages, the systems were not ganic dissolved solids (IDS) between influent and effluent was measured. If this IDS was all taken up by OHOs (and did not form precipitates in the reactor), then the $\mathrm{f}_{\mathrm{iOHO}}$ would have to be 0.45 , which is much too high. In I12 (see also Wentzel et al., 2002), the measured influent ISS/COD $\left(\mathrm{X}_{\mathrm{Ioi}} / \mathrm{S}_{\mathrm{ti}}\right)$ ratio was $0.093 \mathrm{mgISS} /$ $\mathrm{mgCOD}, 3$ times higher than the I1 1 influent ISS/COD ratio. This high influent ISS/COD ratio cannot be accounted for by the measured reactor ISS, even with $\mathrm{f}_{\text {іОно }}=0.0$. The highest value that the influent ISS/COD ratio can take into account for the measured reactor ISS is $0.036 \mathrm{mgISS} / \mathrm{mgCOD}$, which is close to the measured influent ISS/COD ratio for I11. This means that in this investigation either dissolution of influent ISS took place in the reactor or the measured influent ISS was too high. When modelling this data, Wentzel et al. (2002) found that only $20 \%$ of the measured influent ISS became enmeshed in the mixed liquor if $\mathrm{f}_{\text {iОно }}=0.17$ operated for a long time; so relative to the other sludge ages, the data are few and therefore may not be as reliable as for the longer sludge ages (Table 1). For the $3 \mathrm{SBs}$ of I11, in which the influent ISS was measured (investigation weighted average influent ISS/ COD ratio $=0.031$ ), the $\mathrm{f}_{\text {iОно }}$ is 0.11 . This is quite close to the $\mathrm{f}_{\mathrm{iOHO}}$ $=0.15$ estimated for I3, I5 and I6. The calculated vs. measured reactor and influent ISS concentrations for $\mathrm{I} 11$ with $\mathrm{f}_{\mathrm{iоно}}=0.11$ are shown in Figs. 13 and 14. The correlations are quite good. For I11, the calculated and measured influent and reactor ISS concentrations also correlate reasonably well for $\mathrm{f}_{\text {іоно }}=0.15$ (not shown). For I5 and I6 with $\mathrm{f}_{\text {іоно }}=0.15$, the calculated vs. measured SB average reactor ISS concentrations are shown in Figs. 15 to 18, for which the investigation weighted mean influent ISS/COD ratio = 0.0074 and 0.0077 respectively for artificial wastewater and 0.023 and $0.020 \mathrm{mgISS} / \mathrm{mgCOD}$ for real WW. It can be seen that a good 
13 - WARBURTON et al. (1991) DATA

SLUDGE AGE 5-20d; ISS/OHOVSS= 0.15

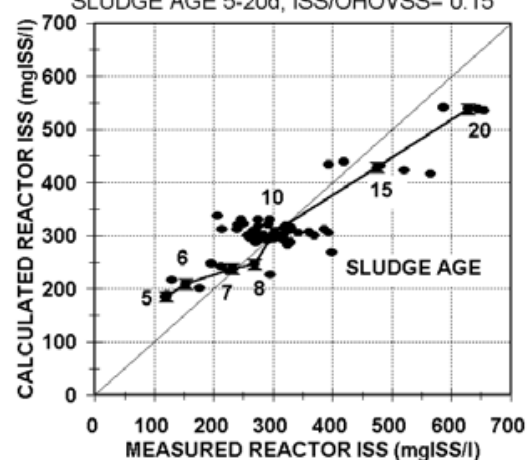

Figure 9

Calculated with OHO ISS content $f_{\mathrm{iOHO}}$ $=0.15 \mathrm{mg} / \mathrm{SS} / \mathrm{mgOHOVSS}$ vs. measured sewage batch average $(\bullet)$ and system average (1S reactor ISS concentration for the seven real WW ND systems of Warburton et al. (1991)

(I3) at sludge ages 5, 6, 7, 8, 10, 15 and $20 \mathrm{~d}$.

13 - WARBURTON et al. (1991) DATA - ISS $/$ OHOVSS $=0.15 \mathrm{mg} / \mathrm{SS} / \mathrm{mgOHOVSS}$

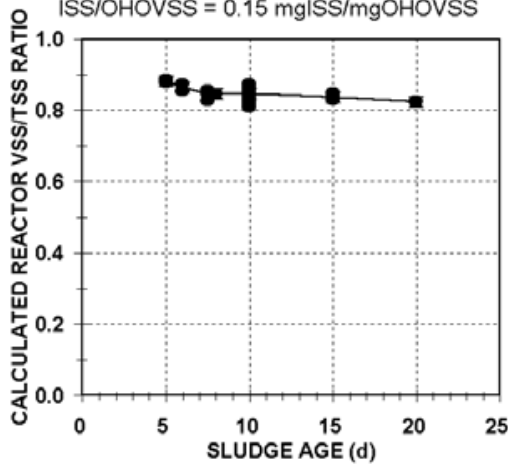

Figure 12

Calculated sewage batch average (•) and system average (m) reactor VSS/ TSS ratio vs. sludge age for the seven real WW ND systems of Warburton et al. (1991) (I3) for OHO ISS content $f_{\text {іОно }}=$ $0.15 \mathrm{mg} / \mathrm{SS} / \mathrm{mgOHOVSS}$

15 - KETLEY et al. (1991) DATA

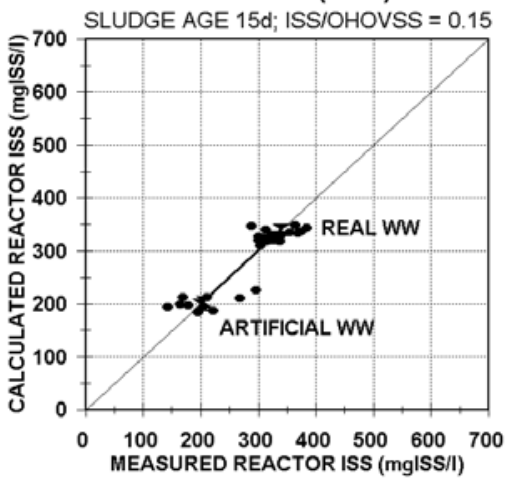

Figure 15

Calculated with $\mathrm{OHO}$ ISS content $f_{\text {іОо }}=0.15 \mathrm{mg} / \mathrm{SS} /$ mgOHOVSS vs. measured sewage batch average (•) and system average (1) reactor ISS concentration for the artificial and real WW ND systems of Ketley et al. (1991) (I5) at $15 d$ sludge age
3 - WARBURTON et al, (1991)

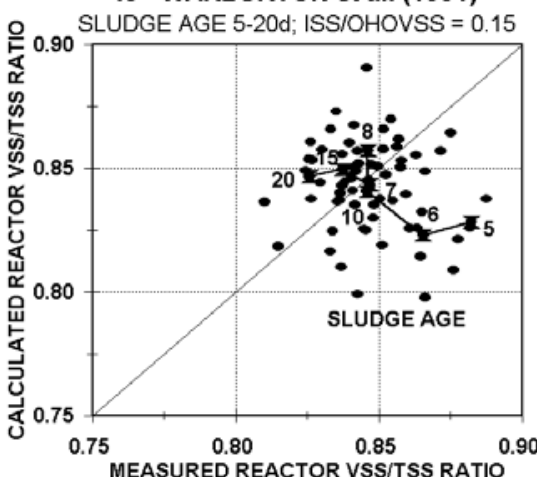

Figure 10

Calculated with OHO ISS content $f_{\text {іОно }}$ $=0.15 \mathrm{mg} / \mathrm{SS} / \mathrm{mgOHOVSS}$ vs measured sewage batch average (•) and system average (1SS reactor ISS concentration for the seven real WW ND systems of Warburton et al. (1991) (I3) at sludge ages 5, 6, 7, 8, 10, 15 and $20 d$

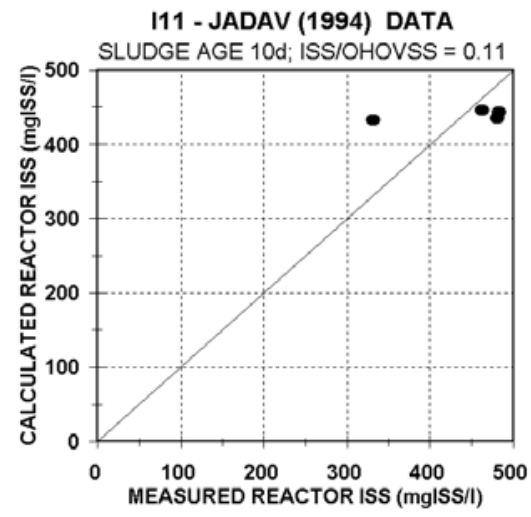

Figure 13

Calculated with $\mathrm{OHO}$ ISS content $f_{\text {}} \mathrm{OHO}=$ $0.11 \mathrm{mg} / \mathrm{SS} / \mathrm{mgOHOVSS}$ vs. measured sewage batch average $(\bullet)$ reactor ISS concentration for the two real WW ND systems of Jadav (1994) (I11) at 10 d sludge age
I3 - WARBURTON et al. (1991) DATA

ISS/OHOVSS $=0.15 \mathrm{mg} / \mathrm{SS} / \mathrm{mgOHOVSS}$

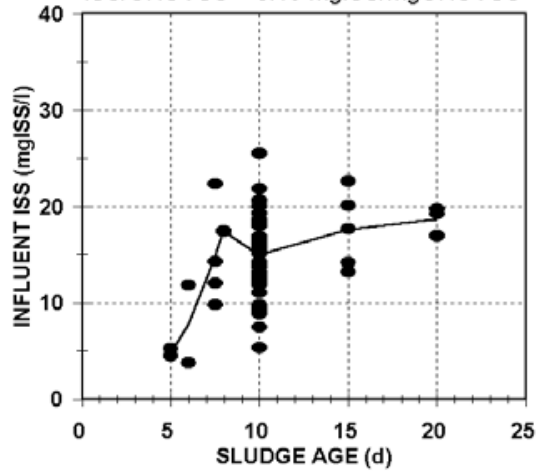

Figure 11

Calculated sewage batch average (•) and system average (M) influent ISS concentration vs. sludge age for the seven real WW ND systems of Warburton et al. (1991) (I3) for $\mathrm{OHO}$ ISS content $f_{\text {iоно }}=0.15 \mathrm{mg} / \mathrm{SS}$ / mgOHOVSS

111 - JADAV (1994) DATA

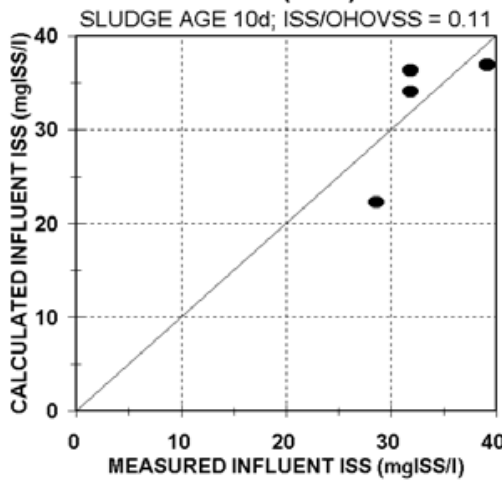

Figure 14

Calculated with $\mathrm{OHO}$ ISS content $f_{\mathrm{iO}}$ $=0.11 \mathrm{mg} / \mathrm{SS} / \mathrm{mgOHOVSS}$ vs . measured sewage batch average $(\bullet)$ reactor ISS concentration for the two real WW ND systems of Jadav (1994) (I11) at $10 \mathrm{~d}$ sludge age

SLUDGE AGE 15d: ISS/OHOVSS $=0.15$

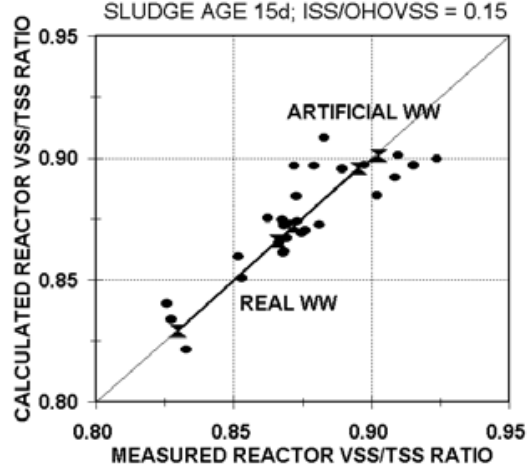

Figure 16

Calculated with $\mathrm{OHO}$ ISS content $f_{\text {іоно }}=0.15 \mathrm{mg} / \mathrm{SS} / \mathrm{mgOHOVSS}$ vs. measured sewage batch average $(\bullet)$ and system average $(\mathbf{m})$ reactor VSS/TSS ratio for the artificial and real WW ND systems of Ketley et al. (1991) (I5) at $15 d$ sludge age 
16 - HULSMAN et al. (1992) DATA

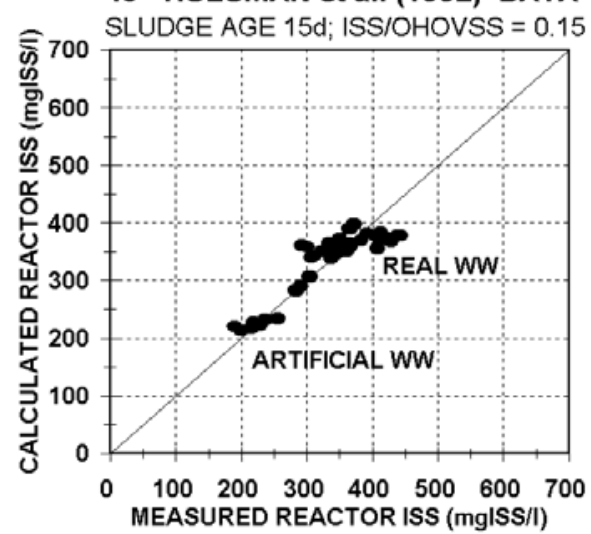

Figure 17

Calculated with $\mathrm{OHO} I S S$ content $f_{\text {іОо }}=0.15 \mathrm{mgISS} /$ mgOHOVSS vs. measured sewage batch average $(\bullet)$ and system average ( $)$ reactor ISS concentration for the artificial and real WW ND systems of Hulsman et al. (1992) (I6) at $15 d$ sludge age

correlation is obtained for these investigations also and the calculated influent ISS concentration for the artificial wastewater is very low, as expected, and for the real wastewater much higher and close to the values measured (I22 - Table 2).

With $\mathrm{f}_{\text {іоно }}$ fixed at $0.15 \mathrm{mgISS} / \mathrm{mgOHOVSS}$, the influent ISS/ COD ratio to account for the measured reactor ISS was determined for the 15 systems of the remaining 8 investigations on FA and ND systems, viz. I4, I7, I13, I15, I16, I19, I20 and I21 (Table 1). These systems represent sludge ages from 3 to $20 \mathrm{~d}$, nominal hydraulic retention times from 7 to $24 \mathrm{~h}$ and feed COD concentrations from 500 to $1000 \mathrm{mgCOD} / \ell$ (Table 1 ). The system weighted average influent ISS/COD ratio vs. sludge age results for all $30 \mathrm{FA}$ and ND systems are shown plotted in Fig. 19. As expected for the artificial wastewater systems (I5 and I6), very low influent ISS/COD ratios are obtained to correctly predict reactor ISS concentration and the real wastewater ratios are 3 to 5 times higher. However, for the real wastewater systems, the system average influent ISS/COD ratios vary over a fairly wide range from 0.016 (I15) to 0.040 (I20) even though the systems were fed wastewater from the same source. This variability appears independent of sludge age. The measured influent ISS/COD ratios from Table 2 are also plotted in Fig. 19. The calculated influent ISS/COD ratios compare reasonably well with the measured ratios, except the I12 measured value, which is three times higher at $0.09 \mathrm{mgISS} / \mathrm{mgCOD}$ (not shown). This value is clearly an outlier from all the other FA and ND systems and measured influent ISS/COD ratios in the database. Because a large set of reliable measurements of influent ISS are not available in the database, it could not be established whether the variability in the calculated influent ISS/COD ratio is real and due to the nature of the wastewater batches collected from the wastewater treatment plant, or inadequacy in the model structure. Clearly, investigations into the measurement of the ISS content of wastewater (raw and settled) are required to develop both suitable analytical methods and a larger database on wastewater ISS concentrations (see below).

Figure 20 shows, vs. sludge age, the relative proportion of the influent and OHO ISS in the reactor and the VSS/TSS ratio for the measured Mitchells Plain influent ISS/COD of 0.031 and an OHO ISS content ( $\mathrm{f}_{\text {іОно }}$ ) of $0.15 \mathrm{mgISS} / \mathrm{mgOHOVSS}$. It can be seen that while the mixed liquor VSS/TSS ratio remains approximately constant, which is in conformity with observation, the percentage
16 - HULSMAN et al. (1992) DATA

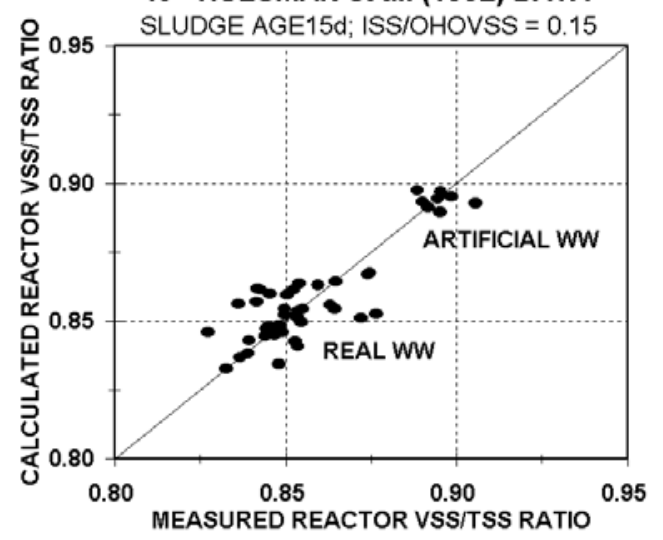

Figure 18

Calculated with OHO ISS content $f_{\text {іОно }}=0.15 \mathrm{mg} / \mathrm{SS} /$ mgOHOVSS vs. measured sewage batch average $(\bullet)$ and system average (1) reactor VSS/TSS ratio for the artificial and real WW ND systems of Hulsman et al. (1992) (I6) at $15 d$ sludge age

ALL 30 ND SYSTEMS ISS/OHOVSS $=0.15 \mathrm{mg} / \mathrm{SS} / \mathrm{mgOHOVSS}$

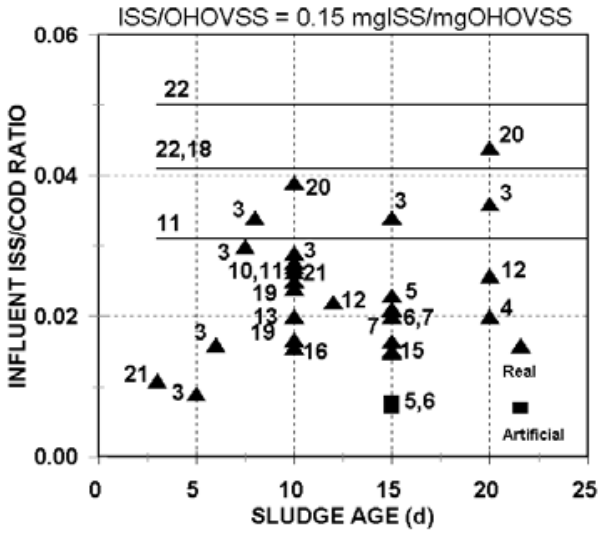

Figure 19

Calculated system average influent ISS concentration (as a ratio of the influent $C O D$ concentration) vs. sludge age for the

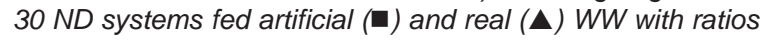
measured in the laboratory (line, 111) and at the source WWTP (lines, 118, 122)

MITCHELLS PLAIN WW INFLUENT ISS/COD $=0.031 ;$ fiOHO $=0.15$

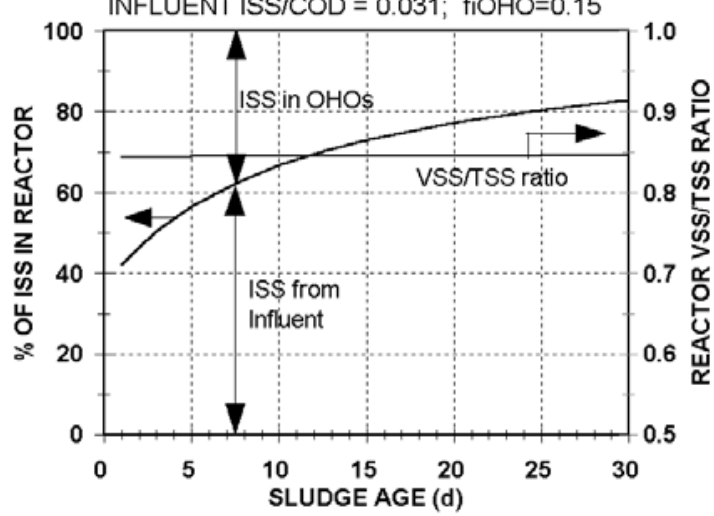

Figure 20

$\%$ of reactor ISS from the influent and in OHOs and reactor VSS/ TSS ratio vs. sludge age for the Mitchells Plain WWTP measured influent ISS/COD ratio of $0.031 \mathrm{mg} / \mathrm{SS} / \mathrm{mgCOD}$ and OHO ISS content of $0.15 \mathrm{mg} / \mathrm{SS} / \mathrm{mgOHOVS}$ 


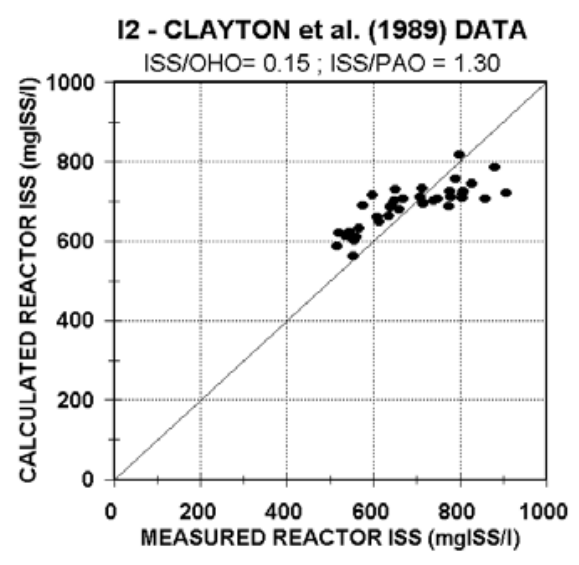

Figure 21

Calculated vs. measured sewage batch average reactor ISS concentration $(\bullet)$ for OHO and PAO ISS content ( $f_{\text {оОно }}$ and $f_{\text {ipAO }}$ ) of 0.15 and $1.30 \mathrm{mg} / \mathrm{SS} / \mathrm{mgVSS}$ for the $>90 \%$ aerobic

$P$ uptake BEPR MUCT system of Clayton et al. (1989) at $18 d$ sludge age

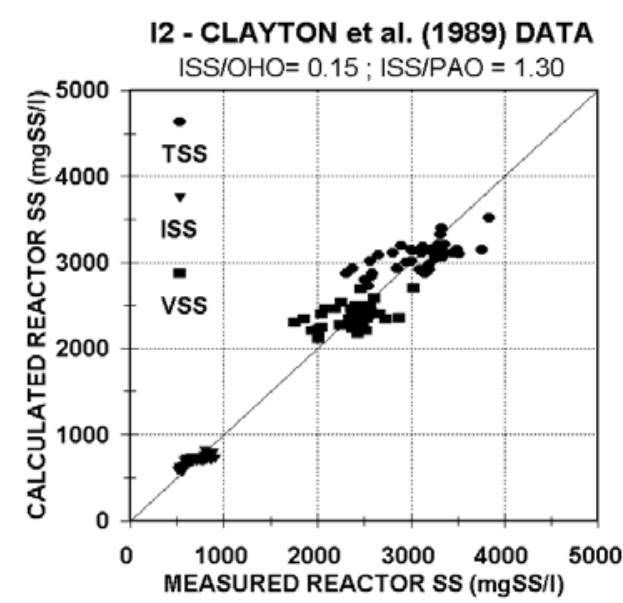

Figure 22

Calculated vs. measured sewage batch average reactor ISS ( $\boldsymbol{\nabla}$ ), VSS ( $\mathbf{\square})$ and TSS $(\bullet)$ concentrations for OHO and PAO ISS content ( $f_{\text {iOHO }}$ and $f_{\text {iPAO }}$ ) of 0.15 and $1.30 \mathrm{mg} / \mathrm{SS} / \mathrm{mgVSS}$ for the $>90 \%$ aerobic $P$ uptake BEPR MUCT system of Clayton et al. (1989) at 18 d sludge age

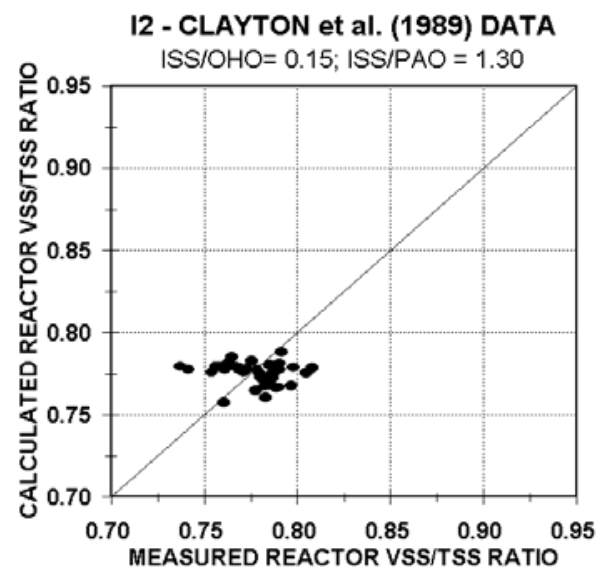

Figure 23

Calculated vs. measured sewage batch average reactor VSS/

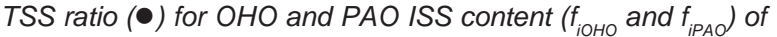
0.15 and $1.30 \mathrm{mg} / \mathrm{SS} / \mathrm{mgVSS}$ for the $>90 \%$ aerobic $P$ uptake BEPR MUCT system of Clayton et al. (1989) at $18 \mathrm{~d}$ sludge age of the ISS in the reactor originating from the influent increases from about $60 \%$ at $5 \mathrm{~d}$ sludge age to $92 \%$ at $30 \mathrm{~d}$. This increase arises because influent ISS mass accumulates in proportion to sludge age (Eq. 1); and the $\mathrm{OHO}$ active fraction $\left(\mathrm{f}_{\text {avOHO}}\right.$ ) decreases with sludge age. This demonstrates that modelling the observed relative insensitivity of the VSS/TSS ratio in the reactor to sludge age by recognising only influent ISS accumulation is not possible - an ISS contribution by the OHOs is required to do this. Including an ISS content in the $\mathrm{OHO}$ endogenous residue did not improve the correlation and because this does not conform to the conceptual basis of this ISS model, i.e. the organism ISS is principally formed from intra-cellular inorganic dissolved solids (IDS) in the test procedure, including ISS in the unbiodegradable organics was not considered further.

\section{Combining the OHO and PAO ISS contents for NDBEPR systems fed real wastewater}

The $\mathrm{f}_{\text {iPAO }}$ fixed at 1.30 from the enhanced PAO cultures and $\mathrm{f}_{\text {iOно }}$ fixed at 0.15 from the FA and ND systems fed artificial and real wastewater, were applied to two NDBEPR systems fed real wastewater, i.e. the I 2 system and the Experimental system of I14. In these two systems, the P uptake was predominantly aerobic (> 90\%). The calculated vs. measured reactor ISS, VSS and TSS concentrations and the VSS/TSS ratio are shown in Figs. 21 to 23. A good correlation was obtained indicating that no refinement of the $\mathrm{f}_{\mathrm{iPAO}}$ and $\mathrm{f}_{\text {іОно }}$ values was necessary. Even though the investigations were conducted a decade apart, of concern was that influent ISS/COD ratio required to obtain a good match between the predicted and measured data was significantly different; 0.022 $\mathrm{mgISS} / \mathrm{mgCOD}$ for I 2 and 0.004 for I14. Although a lower value was expected for I14 because landfill leachate (with no ISS) equivalent to about $200 \mathrm{mgCOD} / \ell$ was dosed to the system, the $0.004 \mathrm{mgISS} / \mathrm{mgCOD}$ value is very low and below the artificial WW values found for I5 and I6. This indicates that some inconsistencies may be present in the ISS model (Eq 2).

When $\mathrm{f}_{\mathrm{iPAO}}=1.30 \mathrm{mg}$ ISS $/ \mathrm{mgPAOVSS}$ for a PAO P content $\left(f_{\mathrm{XBGP}}\right)=0.38 \mathrm{mgP} / \mathrm{mgPAOVSS}$ was applied to the systems with significant anoxic $\mathrm{P}$ uptake ( $>20 \%$ ), poor calculated vs. measured reactor ISS correlations and inconsistent influent ISS/COD ratios were obtained. For significant anoxic P uptake $(>20 \%)$, the calculated $\mathrm{P}$ content of the PAOs $\left(\mathrm{f}_{\mathrm{XBGP}}\right)$ was lower than 0.38 and ranged between 0.10 (Exp of I10 and M2 of I9) and $0.30 \mathrm{mgP} /$ mgPAOVSS (I17 and Cntl of I14). The lower the P content of the PAOs $\left(\mathrm{f}_{\mathrm{XBGP}}\right)$ below 0.38 , the lower the ISS content below 1.30. Accordingly a linear relationship was established between the polyphosphate and ISS contents of the PAOs. Following the ASM models, the $\mathrm{P}$ content of the PAO biomass and polyphosphate are considered separately. Accepting that without polyphosphate, the $\mathrm{P}$ and ISS content of PAOs is the same as OHOs, i.e. $\mathrm{f}_{\mathrm{XBGPBM}}=0.03$ $\mathrm{mgP} / \mathrm{mgPAOVSS}$ and $\mathrm{f}_{\text {іРАовм }}=0.15 \mathrm{mgISS} / \mathrm{mgPAOVSS}$, and that ISS content of the polyphosphate adds to this, then the combined ISS content of PAOs $\left(\mathrm{f}_{\mathrm{iPAO}}\right)$ is given by:

$$
\mathrm{f}_{\text {iPAO }}=3.286 \mathrm{f}_{\text {XBGPP }}+\mathrm{f}_{\text {iPAOBM }} \text { mg ISS/mgPAOVSS }
$$

$$
\begin{aligned}
& \text { where: } \\
& \begin{array}{rl}
\mathrm{f}_{\mathrm{XBGPP}}= & \text { polyphosphate content of PAOs (mg poly- } \\
& \text { phosphate/mgPAOVSS) } \\
= & \mathrm{f}_{\text {XBGP }}-\mathrm{f}_{\text {XBGPBM }} \\
= & \text { total } \mathrm{P} \text { content of PAOs } \\
\mathrm{f}_{\mathrm{XBGP}} & \mathrm{P} \text { content of the PAO cell mass } \\
\mathrm{f}_{\mathrm{XBGPBM}}= & 0.03 \mathrm{mgP} / \mathrm{mgPAOVSS} \\
3.286= & \text { ISS } \mathrm{P} \text { ratio of polyphosphate }
\end{array}
\end{aligned}
$$




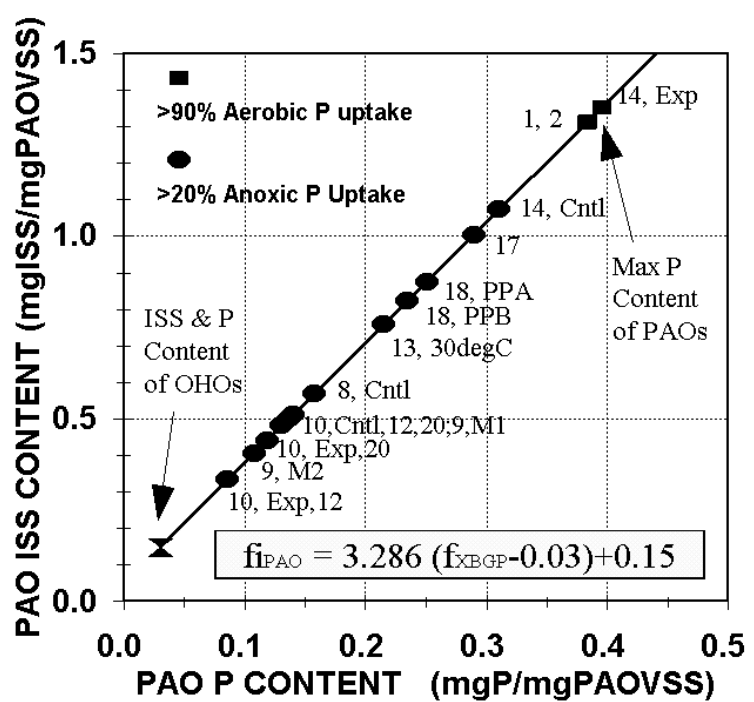

Figure 24

Estimated PAO inorganic solids (ISS) content ( $\left.f_{\text {iPAd }}\right) v s$. $P A O P$ content $\left(f_{X B G P}\right)$ for $>90 \%$ aerobic $P$ uptake BEPR (ш) and variable anoxic-aerobic $P$ uptake $B E P R(\bullet)$ in the 18 NDBEPR systems of investigations $11,12,18,19,110,113,114,117$ and 118 based on the measured $f_{\text {IPAO }}$ value in the four enhanced $P A O$ culture systems (I1) on one extreme $\left(f_{\text {iPAO }}=1.30\right.$, $f_{X B G P}=0.38$, ) and the $P$ content of OHOs on the other $\left(f_{i P A O}=0.15, f_{X B G P}=0.03\right.$,

A plot of PAO ISS content vs. PAO P content is given in Fig. 24. The ISS/P ratio of the polyphosphate in Eq. (3) is the slope of the line in Fig. 24 and was obtained from the ISS and P content of the enhanced PAO culture systems (I1), i.e. >90\% aerobic P uptake BEPR and the $\mathrm{P}$ and ISS content determined for OHOs, viz. $\left(\mathrm{f}_{\mathrm{iPAO}}\right.$ $\left.-\mathrm{f}_{\text {iPAOBM }}\right) /\left(\mathrm{f}_{\text {ХBGP }}-\mathrm{f}_{\text {XBGPBM }}\right)=\mathrm{f}_{\text {iPAOPP }} / \mathrm{f}_{\text {XBGPP }}=(1.30-0.15) /(0.38-0.03)$ $=1.15 / 0.35=3.286$. This ratio compares closely with the 3.19 $\mathrm{mgISS} / \mathrm{mgP}$ ratio theoretically derived above and with the 3.23 ratio adopted for ASM2 and 2d. However, the PAO biomass ISS content (excluding polyphosphate) of $0.15 \mathrm{mgISS} / \mathrm{mgVSS}$ accepted in this model is very much lower than the $0.332 \mathrm{mgISS} /$ mgVSS value accepted in ASM2 and 2d. Furthermore, in the model proposed here, the endogenous residue (of both OHOs and PAOs) and unbiodegradable particulate organics from the influent do not contain ISS, whereas in ASM2 and 2d, these unbiodegradable organics contain $0.11 \mathrm{mgISS} / \mathrm{mgVSS}$. In both the model developed here and in ASM2 and 2d, influent ISS is included to add directly to the reactor ISS concentration, and hence TSS.

As described above, the P content of the PAOs $\left(f_{\text {XBGP }}\right)$ was calculated with the Wentzel et al. (1990) BEPR model from the measured $\mathrm{P}$ removal and the $\mathrm{PAO}$ active fraction $\left(\mathrm{f}_{\text {avPAO }}\right)$. From this $\mathrm{P}$ content, the ISS content was calculated with Eq. (3), and the results for all 18 NDBEPR systems are shown in Fig. 24. The calculated vs. measured reactor ISS concentrations and VSS/TSS ratios for the 2 systems near the extremes of Eq. 3 are plotted in Figs. 25 to 28 , i.e. system M2 of 19 with $\mathrm{f}_{\text {XBGP }}=0.108 \mathrm{mgP} /$ mgPAOVSS and the system of I17 with $\mathrm{f}_{\mathrm{XBGP}}=0.290$ respectively, which yield from Eq. (3), PAO ISS contents $\left(\mathrm{f}_{\mathrm{iPAO}}\right)$ of 0.41 and 1.14 mgISS/mgPAOVSS respectively. A reasonably good correlation is obtained and the influent ISS/COD ratio for the two investigations also is quite consistent ( 0.050 and 0.035 respectively), indicating that the relationship established between the P and ISS content of the PAOs (Eq. 3) is acceptable. For I18 on 2 parallel pilot scale ( $2 \mathrm{M} \ell / \mathrm{d})$ UCT systems, in which the influent ISS/COD ratio
19 - MUSVOTO et al. (1992) DATA

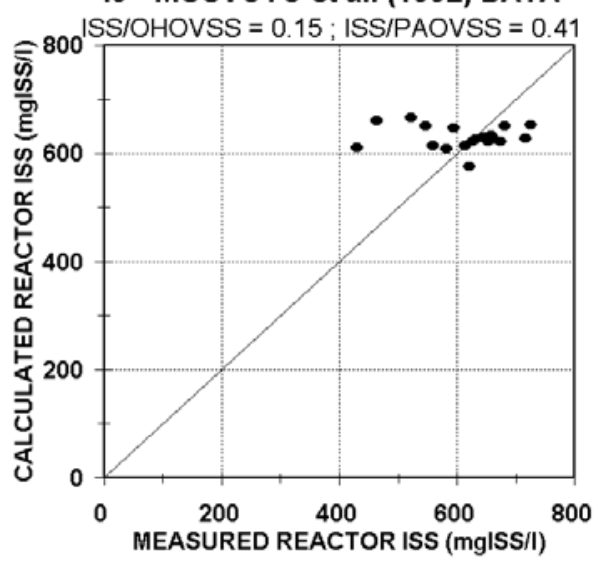

Figure 25

Calculated vs. measured sewage batch average reactor ISS concentration ( $)$ for $\mathrm{OHO}$ and PAO ISS content ( $f_{\text {iOHO }}$ and $f_{\text {IPAO }}$ ) of 0.15 and $0.41 \mathrm{mg} / \mathrm{SS} / \mathrm{mgVSS}$ for the $>20 \%$ anoxic $P$ uptake BEPR UCT system of Musvoto et al. (1992) at $20 \mathrm{~d}$ sludge age

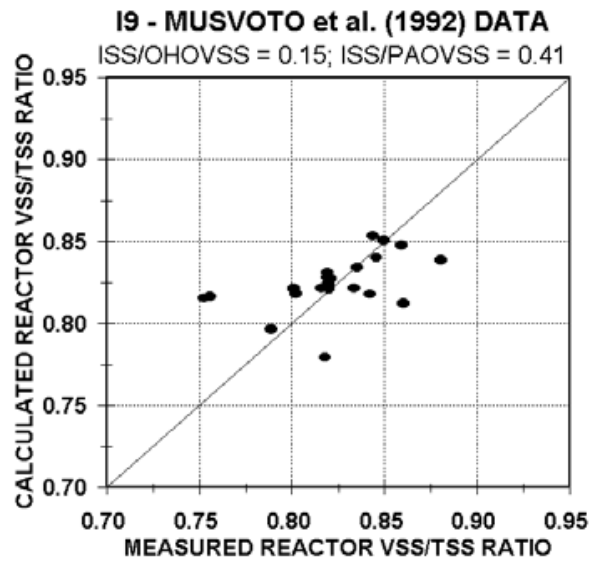

Figure 26

Calculated vs. measured sewage batch average reactor VSS/ TSS ratio $(\bullet)$ for OHO and PAO ISS content ( $f_{\text {iОНО }}$ and $f_{\text {iPAO }}$ ) of 0.15 and $0.41 \mathrm{mg} / \mathrm{SS} / \mathrm{mgVSS}$ for the $>20 \%$ anoxic $P$ uptake BEPR UCT system of Musvoto et al. (1992) at 20 d sludge age

117 - VERMANDE et al. (2000) DATA ISS/OHOVSS $=0.15 ;$ ISS/PAOVSS $=1.14$

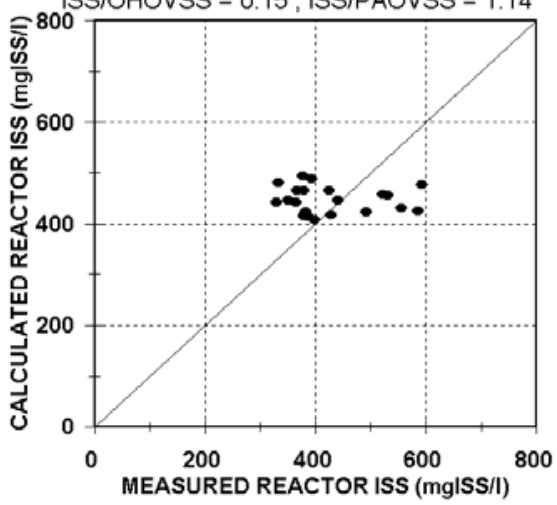

Figure 27

Calculated vs. measured sewage batch average reactor ISS concentration $(\bullet)$ for OHO and PAO ISS content ( $f_{\text {іОНО }}$ and $f_{\text {iPAO }}$ ) of 0.15 and $1.14 \mathrm{mg} / \mathrm{SS} / \mathrm{mgVSS}$ for the $>20 \%$ anoxic $P$ uptake BEPR UCT system of Vermande et al. (2000) at $10 \mathrm{~d}$ sludge age 
I17 - VERMANDE et al. (2000) DATA

ISS/OHOVSS $=0.15 ;$ ISS/PAOVSS $=1.14$

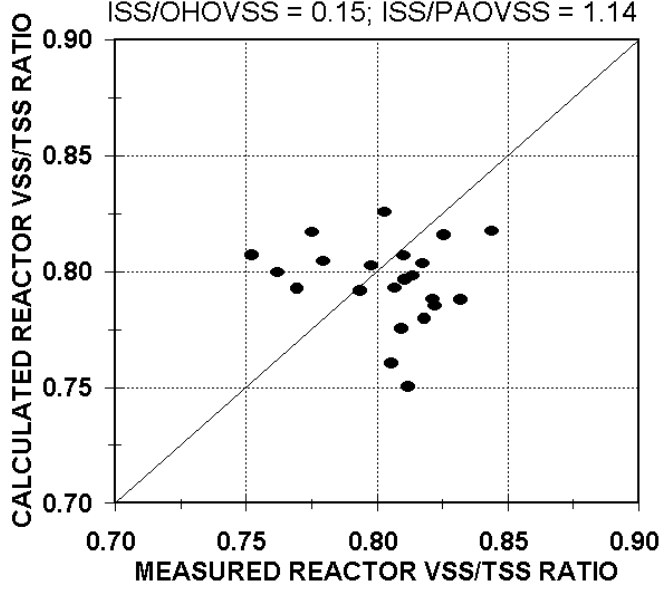

Figure 28

Calculated vs. measured sewage batch average reactor VSS/ TSS ratio $(\bullet)$ for OHO and PAO ISS content $\left(f_{\text {iOHO }}\right.$ and $f_{\text {iPAO }}$ ) of

0.15 and $1.14 \mathrm{mg} / \mathrm{SS} / \mathrm{mgVSS}$ for the $>20 \%$ anoxic $P$ uptake BEPR UCT system of Vermande et al. (2000) at $10 \mathrm{~d}$ sludge age

118 - HERCULES et al. (2002) DATA ISS $/$ OHOVSS $=0.15 ;$ ISS $/$ PAOVSS $=0.88$

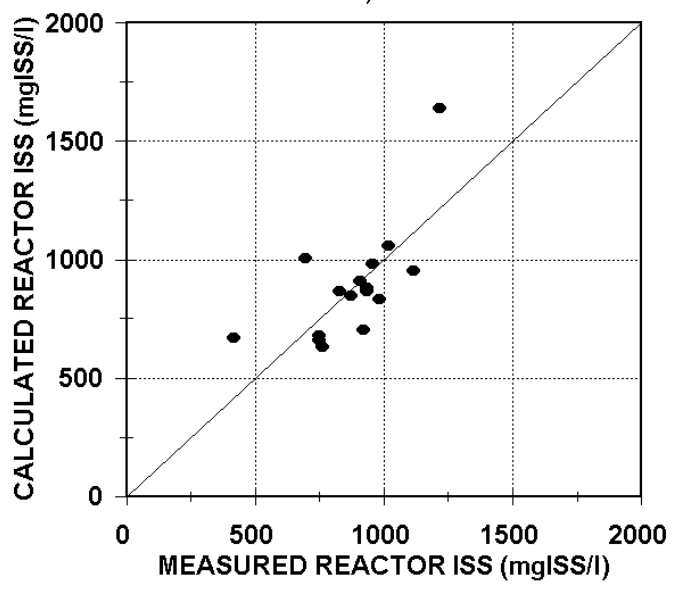

Figure 29

Calculated vs. measured steady state period average reactor ISS concentration ( $\bullet$ ) for OHO and PAO ISS content ( $f_{i \mathrm{OHO}}$ and $f_{\text {iPAO }}$ ) of 0.15 and $0.88 \mathrm{mg} / \mathrm{SS} / \mathrm{mgVSS}$ for the two $2 \mathrm{Me} / \mathrm{d}$ UCT system pilot plants of Hercules et al. (2002) at 13.5 d sludge age for anoxic-aerobic $P$ uptake BEPR and with high nitrate recycle to the anaerobic reactor

$\left(\mathrm{X}_{\mathrm{Ioi}} / \mathrm{S}_{\mathrm{ti}}\right)$ was measured, the calculated vs. measured reactor and influent ISS concentrations are shown in Figs. 29 and 30 respectively, for which $\mathrm{f}_{\text {іОно }}$ is unchanged at 0.15 and $\mathrm{f}_{\text {іРАо }}=0.88$ and 0.82 obtained from the observed P removal. For the reactor ISS concentration (Fig. 29), the correlation is reasonable. The measured and calculated influent ISS/COD ratios are 0.041 and $0.025 \mathrm{mgISS} /$ mgCOD respectively. The correlation between measured and calculated influent ISS/COD ratios is not very good and generally the calculated influent ISS concentrations are lower (with some-ve values) than those measured (Fig. 30). However, as in I12, it is possible that there is some bias in the measured values due to the experimental method, discussed below.

The above approach was followed for the remaining 8 NDBEPR
I18 - HERCULES et al. (2002) DATA

ISS $/$ OHOVSS $=0.15 ;$ ISS $/$ PAOVSS $=0.88$

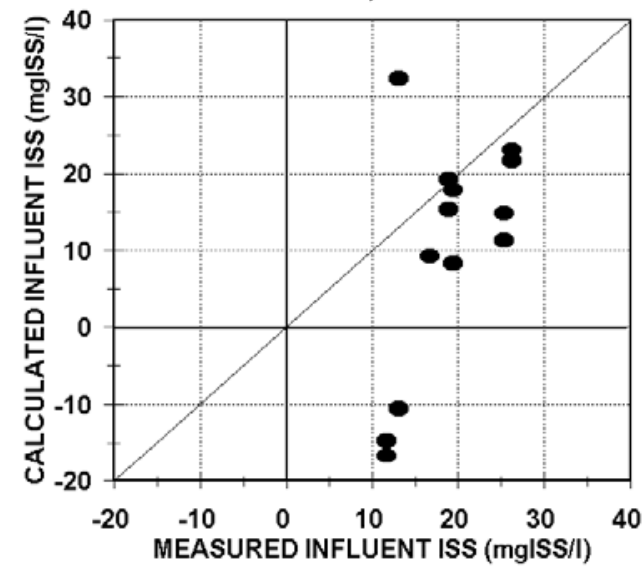

Figure 30

Calculated vs. measured steady state period average influent ISS concentration ( $\bullet$ ) for OHO and PAO ISS content (f ${ }_{\text {іОно }}$ and $f_{\text {iPAO }}$ ) of 0.15 and $0.88 \mathrm{mg} / \mathrm{SS} / \mathrm{mgVSS}$ for the two $2 \mathrm{Ml} / \mathrm{d}$ UCT system pilot plants of Hercules et al. (2002) at $13.5 \mathrm{~d}$ sludge age for anoxic-aerobic $P$ uptake BEPR and with high nitrate recycle to the anaerobic reactor

systems of I8 to I11 and I13 and the calculated influent ISS/COD ratios from all 18 NDBEPR systems are shown plotted vs. sludge age in Fig. 31, and together with the ratios from the 30 FA and ND systems in Fig. 32. It can be seen that the calculated influent ISS/ COD ratios for the NDBEPR systems tend to fall below the measured ratios (lines), but superimpose well over the FA and ND ratios. Considering the significantly higher ISS in the PAO biomass ( 3 to 6 times) compared with OHO biomass, if there were significant error in the model, negative or very high influent ISS/ COD ratios would be obtained, but this is not the case. The model can therefore be accepted as having the required relative sensitivity to the ISS contents of the OHOs and PAOs and the influent ISS concentration.

Figure 33 shows, vs. sludge age, the relative contribution to the reactor ISS concentration by the influent ISS and the ISS in the OHOs and PAOs; the last for $>90 \%$ aerobic $\mathrm{P}$ uptake BEPR $\left(\mathrm{f}_{\text {iPAO }}\right.$ $=1.30 \mathrm{mgISS} / \mathrm{mgPAOVSS}$ ), and the VSS/TSS ratio for the measured Mitchells Plain influent ISS/COD of 0.031 and an OHO ISS content of $0.15 \mathrm{mgISS} / \mathrm{mgOHOVSS}$. It can be seen that while the mixed liquor VSS/TSS ratio remains in a narrow range between 0.70 and 0.75 with sludge age from 5 to $30 \mathrm{~d}$, which is in conformity with observation, the ISS in the PAOs is around $60 \%$ of the total ISS; the \% of the ISS in the reactor originating from the influent increases from about $20 \%$ at $5 \mathrm{~d}$ sludge age to $40 \%$ at $30 \mathrm{~d}$; and the OHOs contribute relatively little (20 to $10 \%)$ to the reactor ISS. Because of the high ISS content of PAOs, NDBEPR systems have significantly lower VSS/TSS ratios than ND systems and the influent ISS contributes between a quarter and a third of the total ISS in the reactor.

\section{Determination of influent ISS}

A possible source of bias in the ISS concentration measurement is from the total dissolved solids (TDS) of the residual water before drying. If a $3000 \mathrm{mgTSS} / \ell$ sample is centrifuged in a $50 \mathrm{~m} \ell 30 \mathrm{~mm}$ diameter tube with hemispherical bottom, the residual water is about $10 \mathrm{~m} \ell$, which at a TDS of $500 \mathrm{mg} / \ell$, contributes $5 \mathrm{mgISS}$. If 


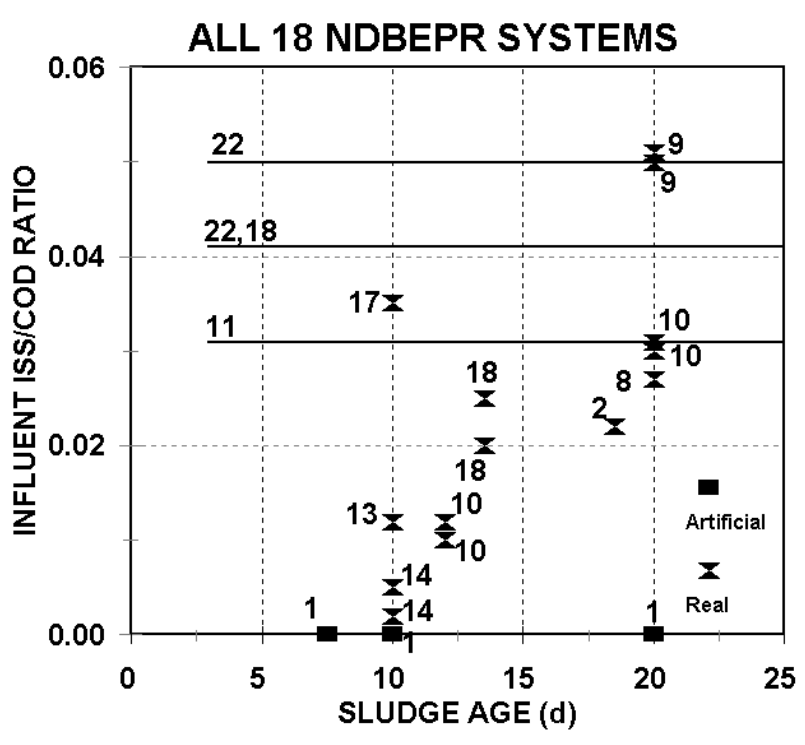

Figure 31

Calculated system average influent ISS concentration (as a ratio of the influent $C O D$ concentration) vs. sludge age for the 18 NDBEPR systems fed artificial $(\square, 1)$ and real (NDBEPR) WW with ratios measured in the laboratory (line, 111) and at the source WWTP (lines, 118, 122)

the VSS/TSS ratio of the sludge is 0.80 , this $5 \mathrm{mg}$ ISS is $5 / 30=17 \%$. Solid/liquid separation in the influent TSS and ISS concentration determination is usually done through weighed ashless filter papers (as was done in I1 1 and I18). If $1 \ell$ influent is filtered and again 10 $\mathrm{m} \ell$ residual water remains in the filter paper and solids before drying, then 5mgTDS is added to the influent ISS. For influent ISS concentrations around 20 to $40 \mathrm{mg} / \ell$, this is a bias of 25 to $12 \%$ upwards. The same applies if the ISS is measured as the difference between the total inorganic solids of unfiltered and filtered samples, as was done in I12. Moreover, the filter pore size is important because if too large, fine clay may pass through the filter medium. Clearly the TDS of the sample, the sample size, solid/liquid separation method and the solids concentration can significantly bias the ISS concentration upwards, causing a considerable loss of accuracy.

Precision is also a problem in the influent ISS method. After the initial drying step for the TSS, the filter paper, with its solids, is placed in a weighed crucible of mass generally $>25 \mathrm{~g}$ and incinerated at $600^{\circ} \mathrm{C}$. The ash residue in the crucible is the ISS, which is the difference between two large masses, around 1000 times greater than the ISS mass. This causes large variance in the ISS concentration.

To try to overcome these problems of accuracy and precision in the influent ISS measurement, various filtration media were tested. The best one was found to be glass fibre filters (GF/C Schleicher and Schüll GF52) because:

- their pore size is small enough $(<1.0 \mu)$ to retain even very fine clay (tests with kaolin yielded $>99 \%$ recovery);

- precision improved significantly because the glass fibre filters acted as very light mass crucibles - however, they needed to be pretreated by incineration for $>6 \mathrm{~h}$ prior to use to stabilise their mass; and

- their moisture retention was negligible.

This method was therefore used to measure the influent ISS/COD
ALL 30 ND and 18 NDBEPR SYSTEMS

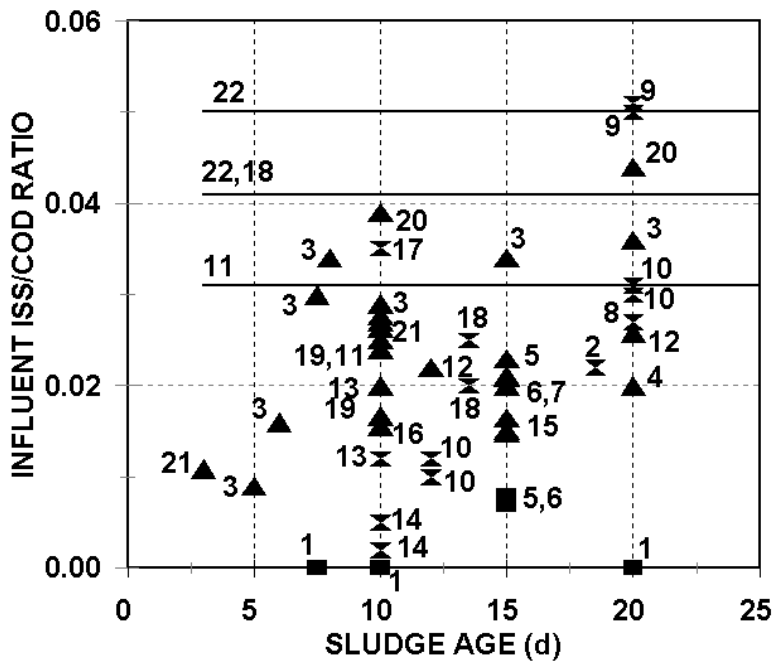

Figure 32

Calculated system average influent ISS concentration (as a ratio of the influent $C O D$ concentration) vs. sludge age for the $30 \mathrm{ND}$ and 18 NDBEPR systems fed artificial (घ, 5and $6 \mathrm{ND}$ 1 NDBEPR) and real $(\mathbf{\Lambda} N$, $N D B E P R) W W$ with ratios measured in the laboratory (line, 111) and at the source WWTP (lines, 118, 122)

MITCHELLS PLAIN WW

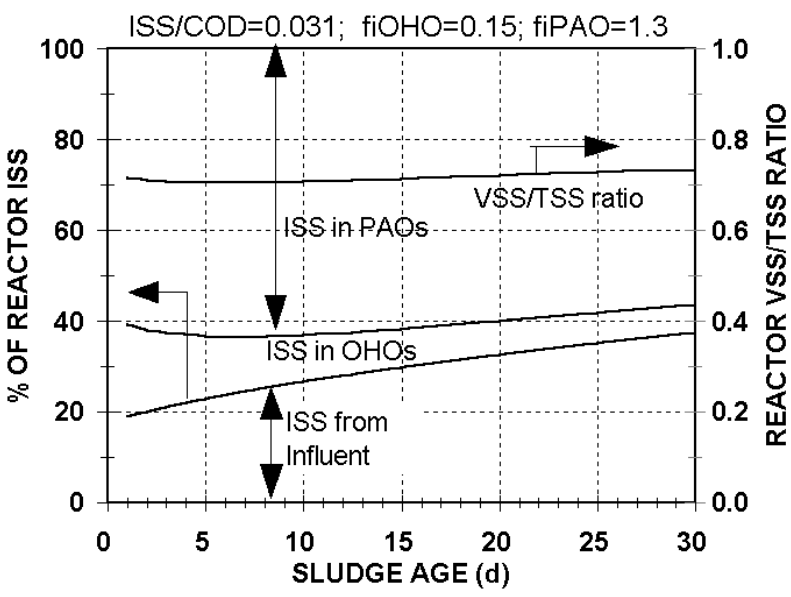

Figure 33

$\%$ of reactor ISS from the influent and in OHOs and PAOs (for $>90 \%$ aerobic $P$ upake BEPR) and reactor VSS/TSS ratio vs. sludge age for the Mitchells Plain WWTP measured influent ISS/COD ratio of $0.031 \mathrm{mg} / \mathrm{SS} / \mathrm{mgCOD}$ and $\mathrm{OHO}$ and PAO ISS content of $0.15 \mathrm{mg} / \mathrm{SS} / \mathrm{mgOHOVSS}$ and 1.30 mgISS/mgPAOVSS

ratio of raw and settled wastewater at the Mitchell Plain WWTP (I22, Table 2). It is recommended that this method be adopted for measurement of influent ISS to build up a database for this wastewater characteristic for design.

\section{Sensitivity of the reactor VSS/TSS ratio}

The experimental data from the 21 investigations show that the measured reactor ISS concentration, and hence the VSS/TSS ratio, is influenced by the influent ISS concentration, BEPR and sludge 


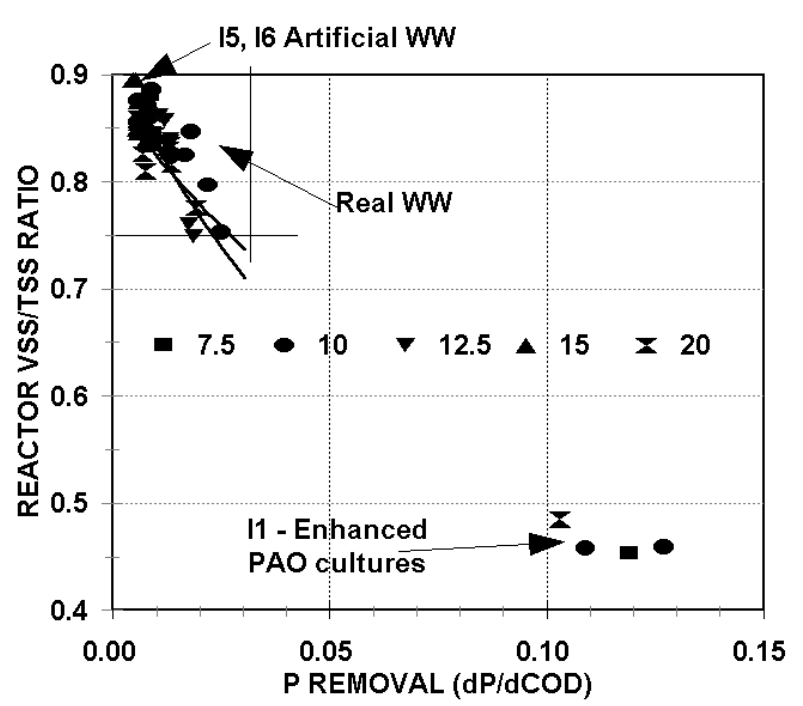

Figure 34

Measured (points) and calculated (lines) reactor VSS/TSS ratio vs. $P$ removal for all 48 real and artificial wastewater systems of investigations 1 to 21 grouped in sludge ages 7.5 , $10,12.5,15$ and $20 d$

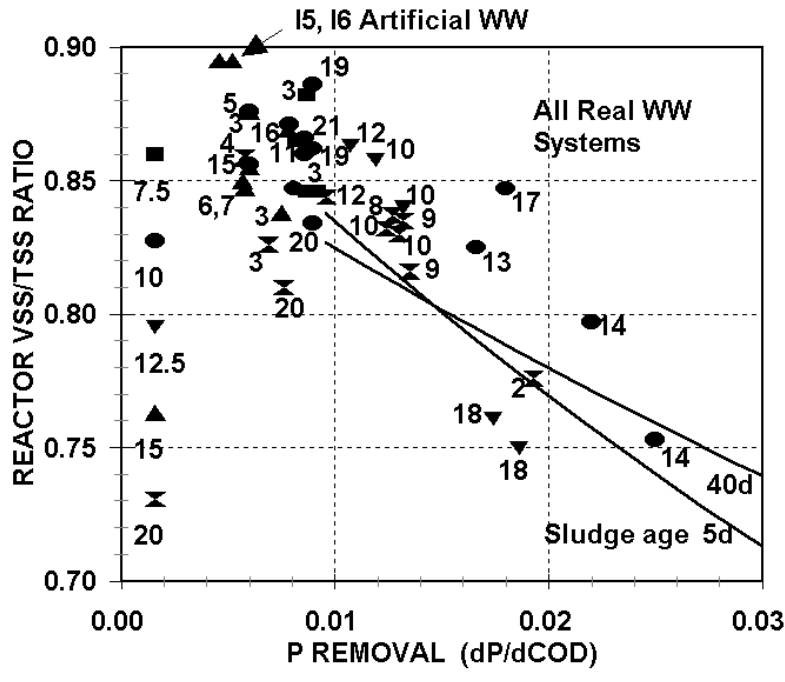

Figure 35

Measured (points) and calculated (lines) reactor VSS/TSS ratio vs. $P$ removal for all 44 real (42) and artificial (2) wastewater systems of investigations 2 to 21 grouped in sludge ages $7.5,10,12.5,15$ and 20 days (enlargement of top right hand corner of Fig. 34)
TABLE 3

Model predicted reactor VSS/TSS ratio for sludge ages from 2 to $40 \mathrm{~d}$ (last column) for raw and settled wastewater characteristics (first column), influent ISS/COD ratio (second column) and type of activated sludge

\begin{tabular}{|c|c|c|c|c|}
\hline \multicolumn{2}{|l|}{ Raw wastewater } & Influent & PAO P content & VSS/TSS \\
\hline $\mathrm{COD}(\mathrm{mgCOD} /)$ & 750 & 0.050 & ND (No BEPR) & 0.78 to 0.81 \\
\hline RBCOD (mgCOD/ ) & 146 & 0.050 & 0.15 (Ax BEPR) & 0.75 to 0.74 \\
\hline USCOD $(\mathrm{mgCOD} /)$ & 53 & 0.050 & 0.38 (Aer BEPR) & 0.68 to 0.70 \\
\hline UPCOD $(\mathrm{mgCOD} /)$ & 113 & 0.030 & ND (No BEPR) & 0.84 to 0.85 \\
\hline $\operatorname{ISS}_{\text {high }}(\mathrm{mgISS} /)$ & 38 & 0.030 & 0.15 (Ax BEPR) & 0.78 to 0.80 \\
\hline $\mathrm{ISS}_{\text {low }}(\mathrm{mgISS} /)$ & 23 & 0.030 & 0.38 (Aer BEPR) & 0.71 to 0.74 \\
\hline \multicolumn{2}{|l|}{ Settled wastewater } & $\begin{array}{l}\text { Influent D } \\
\text { ISS/CO }\end{array}$ & PAO P content & VSS/TSS \\
\hline $\mathrm{COD}(\mathrm{mgCOD} /)$ & 450 & 0.035 & ND (No BEPR) & 0.76 to 0.81 \\
\hline RBCOD (mgCOD/ ) & 146 & 0.035 & 0.15 (Ax BEPR) & 0.70 to 0.69 \\
\hline USCOD $(\mathrm{mgCOD} /)$ & 53 & 0.035 & 0.38 (Aer BEPR) & 0.60 to 0.61 \\
\hline UPCOD (mgCOD/ ) & 18 & 0.015 & ND (No BEPR) & 0.85 to 0.87 \\
\hline $\mathrm{ISS}_{\text {high }}(\mathrm{mgISS} /)$ & 16 & 0.015 & 0.15 (Ax BEPR) & 0.73 to 0.75 \\
\hline $\operatorname{ISS}_{\text {low }}(\mathrm{mgISS} /)$ & 7 & 0.015 & 0.38 (Aer BEPR) & 0.60 to 0.65 \\
\hline
\end{tabular}

RBCOD, USCOD, UPCOD are respectively the influent readily biodegradable, unbiodegradable solubleand unbiodegradable particulate COD concentrations. system (PAO P content, third column)

with VSS/TSS ratio decreasing significantly as $\Delta \mathrm{P} / \Delta \mathrm{COD}$ increases. In contrast, no significant effect of sludge age on the reactor VSS/TSS ratio is evident in the results.

The model shows similar relative sensitivity as the experimental data to BEPR and sludge age. The predicted reactor VSS/TSS ratio for varying magnitude of $\mathrm{P}$ removal $\left(\mathrm{f}_{\mathrm{XBGP}} 0.03\right.$ to $0.38 \mathrm{mgP} /$ mgPAOVSS) for an influent ISS/COD ratio of $0.040 \mathrm{mgISS} / \mathrm{mgCOD}$ is also shown in Figs. 34 and 35 (lines). A better fit is not expected because the influent ISS is fixed at $0.04 \mathrm{mgISS} /$ mgCOD. The predicted VSS/TSS ratios, representing the extremes of sludge age (5 and $40 \mathrm{~d}$ ), follow the same slope as the experimental data. The predicted ratios start at lower values because the upper value (for zero BEPR) is fixed by the influent ISS/COD ratio $=0.040$, higher than found for most of the 48 experimental systems (Fig. 32).

To demonstrate the relative sensitivity of the predicted reactor VSS/TSS ratio to sludge age and magnitude of $\mathrm{P}$ removal, the predicted reactor VSS/TSS ratio for typical South African raw and settled wastewater characteristics, and PAO P content $\left(\mathrm{f}_{\mathrm{XBGP}}\right)$ of $0.03,0.19$ and age. The effect of BEPR and sludge age on the system average VSS/TSS ratio measured in the different systems of the 21 investigations are shown in Fig. 34, which includes the enhanced PAO cultures of I1, and in Fig. 35, which "zooms-in" on the real wastewater systems with VSS/TSS ratios from 0.75 to 0.90 and BEPR of 0.005 to $0.025 \mathrm{mgP}$ removed per $\mathrm{mgCOD}$ removed $[\Delta \mathrm{P} /$ $\left.\Delta \mathrm{COD}=\left(\mathrm{P}_{\text {infl }}-\mathrm{P}_{\text {effl }}\right) /\left(\mathrm{COD}_{\text {infl }}-\mathrm{COD}_{\text {effl }}\right)\right]$. The effect of BEPR is clear,
$0.38 \mathrm{mgP} / \mathrm{mgPAOVSS}$ as representative of ND, anoxic P uptake BEPR and aerobic uptake BEPR systems respectively, is shown in Table 3. Clearly, sludge age has a minor influence on the reactor VSS/TSS ratio. If the estimates of the high and low influent ISS concentrations in Table 3 are reasonable, then the P content of the PAOs has a much larger influence on the reactor VSS/TSS ratio than the influent ISS, with the ratio decreasing markedly for 
increasing PAO P content. For ND systems, the reactor VSS/TSS ratio ranges between 0.78 and 0.85 for raw wastewater and 0.76 and 0.87 for settled wastewater, depending on the influent ISS concentration. For NDBEPR systems with $>90 \%$ aerobic $\mathrm{P}$ uptake BEPR, the reactor VSS/TSS ratio ranges between 0.68 and 0.74 for raw wastewater and 0.60 and 0.65 for settled wastewater. The ratio is lower for settled wastewater than raw wastewater because in settled wastewater a far greater proportion of the influent COD is RBCOD, so a greater proportion of the VSS mass is PAOs.

\section{Application to design}

Because of the relative insensitivity of the VSS/TSS ratio to sludge age, generally assumed for many years in design but now given an experimental and modelling basis, the reactor VSS/TSS ratio can be calculated for different influent ISS/COD ratios. In conformity with the equation structure and symbol system of Ekama et al. (1983), WRC (1984) and Wentzel et al. (1990), the masses of VSS, ISS and TSS in the reactor, the last two calculated with the ISS model, and the VSS/TSS ratio $\left(\mathrm{f}_{\mathrm{i}}\right)$ are given by:

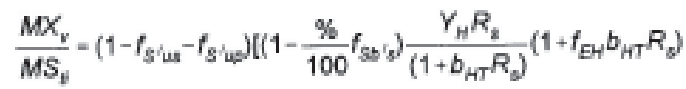

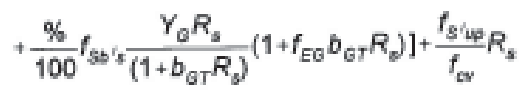

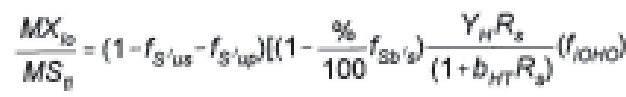

$$
\begin{aligned}
& \left.+\frac{\%}{100} f_{S b^{\prime} s} \frac{Y_{G} R_{s}}{\left(1+b_{G T} R_{g}\right)}\left\{3.286\left(f_{X B G P}-f_{\text {XaGPa }}\right)+f_{\text {iOHo }}\right\}\right]+\frac{X_{\text {iod }}}{S_{v}} R_{s}
\end{aligned}
$$

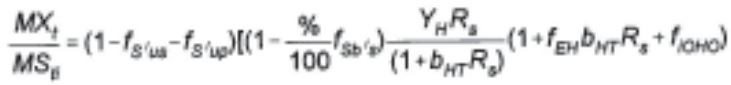

$$
\begin{aligned}
& \left.+\frac{\%}{100} f_{S O / 2} \frac{Y_{0} R_{g}}{\left(1+b_{G T} R_{g}\right)}\left(1+f_{E G} b_{G T} R_{z}+3.286\left(f_{\text {XEGP }}-f_{\text {XEGPEW }}\right)+f_{\text {PAOEW }}\right)\right]
\end{aligned}
$$

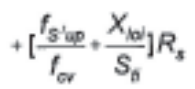$$
t_{j}=\frac{M X_{v}}{M X_{t}}
$$

where:

$\mathrm{MX}_{\mathrm{v}}=$ VSS mass in reactor $(\mathrm{kgVSS})$

$\mathrm{MS}_{\mathrm{ti}}=$ COD mass load on reactor $(\mathrm{kgCOD} / \mathrm{d})$

$$
=\mathrm{Q}_{\mathrm{i}} \mathrm{S}_{\mathrm{ti}}
$$

$\mathrm{Q}_{\mathrm{i}} \quad=$ average dry weather flow (ADWF, M M /d)

$\mathrm{S}_{\mathrm{ti}} \quad=$ flow weighted average influent COD concentration entering biological reactor $(\mathrm{mgCOD} / \ell)$

$\mathrm{MX}_{\mathrm{Io}}=$ mass of ISS in reactor ( $\left.\mathrm{kgTSS}\right)$

$\mathrm{MX}_{\mathrm{t}}=$ mass of TSS in reactor (kgTSS)

$\mathrm{f}_{\text {S'up }}=$ influent unbiodegradable particulate COD fraction

$\mathrm{f}_{S^{\prime} \text { us }} \quad=$ influent unbiodegradable soluble COD fraction

$\mathrm{f}_{\mathrm{S} \mathrm{S}^{\prime} \mathrm{s}} \quad=$ influent readily biodegradable $(\mathrm{RB})$ COD fraction with respect to biodegradable COD

$\%=$ percentage influent RBCOD taken up by PAOs

$=100 \%$ for enhanced PAO culture systems of
Wentzel et al. (1989a)

$=0$ if system is ND, i.e. no PAOs

$>0$ if system is NDBEPR, increasing with

increasing BEPR (usually 70 to 90 )

$\mathrm{Y}_{\mathrm{H}}, \mathrm{Y}_{\mathrm{G}}=$ yield coefficient for OHOs and PAOs

$=0.45 \mathrm{mgVSS} / \mathrm{mgCOD}$

$\mathrm{b}_{\mathrm{HT}}, \mathrm{b}_{\mathrm{GT}}=$ endogenous respiration rate for OHOs and PAOs at $\mathrm{T}^{\circ} \mathrm{C}$

$=0.24 / \mathrm{d}$ and $0.04 / \mathrm{d}$ respectively at $20^{\circ} \mathrm{C}\left(\theta_{\mathrm{b}}=1.029\right.$ for both)

$\theta_{\mathrm{b}} \quad=$ temperature sensitivity coefficient for endogenous respiration

$\mathrm{R}_{\mathrm{s}} \quad=$ system sludge age (days)

$\mathrm{f}_{\mathrm{EH}}, \mathrm{f}_{\mathrm{EG}}=$ endogenous residue fraction of the OHOs and PAOs

$=0.20$ and 0.25 respectively

$\mathrm{f}_{\mathrm{cv}}=\mathrm{COD} / \mathrm{VSS}$ ratio of organics $=1.48 \mathrm{mgCOD} / \mathrm{mgVSS}$

$\mathrm{f}_{\text {iоно }}=$ inorganic content of OHO cell mass

$=0.15 \mathrm{mgISS} / \mathrm{mgOHOVSS}$

$\mathrm{f}_{\text {iPAOBM }}=$ inorganic content of PAO cell mass (without polyphosphate)

$=0.15 \mathrm{mgISS} / \mathrm{mgPAOVSS}$

$\mathrm{f}_{\mathrm{XBGP}}=$ total $\mathrm{P}$ content of PAOs

$\mathrm{f}_{\mathrm{XBGBM}}=$ Pcontent of PAOcell mass (without polyphosphate)

$=0.03 \mathrm{mgP} / \mathrm{mgPAOVSS}$

$\mathrm{X}_{\mathrm{Ioi}} \quad=$ influent ISS concentration entering biological reactor

$\mathrm{f}_{\mathrm{i}} \quad=$ VSS/TSS ratio of reactor sludge.

In Eqs. (4) to (6), all the influent RBCOD is assumed to be taken up by the PAOs; if this is not the case, then the $\mathrm{f}_{\text {Sb's }}$ ratio needs to be reduced to take account of this. For ND systems, $\mathrm{f}_{\mathrm{Sb}^{\prime} \mathrm{s}}$ must be set to zero to ensure zero growth of PAOs. If this is not done, $\mathrm{MX}_{\mathrm{v}}$ will be incorrectly predicted especially for long sludge age systems because PAOs have a very low endogenous respiration rate compared with OHOs.

A plot of the reactor VSS/TSS ratio (f) vs. influent ISS/COD ratio is given in Figs. 36 and 37 respectively for the raw and settled wastewater characteristics listed in Table 3 for ND systems (no BEPR), anoxic-aerobic $\mathrm{P}$ uptake BEPR (i.e. reduced PAO P content, $\mathrm{f}_{\mathrm{XBGP}}=0.19 \mathrm{mgP} / \mathrm{mgPAOVSS}$ ) and aerobic $\mathrm{P}$ uptake BEPR (i.e. maximum PAO P content, $\mathrm{f}_{\mathrm{XBGP}}=0.38 \mathrm{mgP} /$ mgPAOVSS). The small effect of sludge age is also shown by plotting the $f_{i}$ value for each of the three types of systems at 10 and 30 days sludge age. The influent ISS/COD ratio was measured at the Mitchells Plain WWTP for the raw and settled wastewater at around 0.045 and $0.042 \mathrm{mg} \mathrm{ISS} / \mathrm{mgCOD}$ respectively (Table 2). From Fig. 37 for the Mitchells Plain WWTP, which treats settled wastewater in an ND system at 20 to $30 \mathrm{~d}$ sludge age, the predicted $\mathrm{VSS} / \mathrm{TSS}$ ratio is around 0.80 for the measured influent ISS/COD ratio of 0.040 (Table 2). The year 2002 measured annual average VSS/TSS ratio obtained from plant performance results was around 0.85 . This indicates that either the ISS model predicts the reactor ISS mass too high in relation to the VSS mass, or that the measured influent ISS/COD ratio of 0.040 is too high (Table 2). As indicated in Fig. 32, it is possible that the measured ratio of $0.040 \mathrm{mg}$ ISS/ $\mathrm{mgCOD}$ is on the high-end for Mitchells Plain settled wastewater, even though it was measured at around this value on two separate occasions (Table 2). The laboratory units generally yielded influent ISS/COD ratios for strained raw wastewater (see above) below 0.040 , between 0.015 to $0.030 \mathrm{mgISS} / \mathrm{mgCOD}$. An influent ISS/ COD ratio of 0.021 yields a reactor VSS/TSS ratio of 0.85 . It should be noted that generally influent ISS concentrations are very small in magnitude and what may appear to be a large percentage 


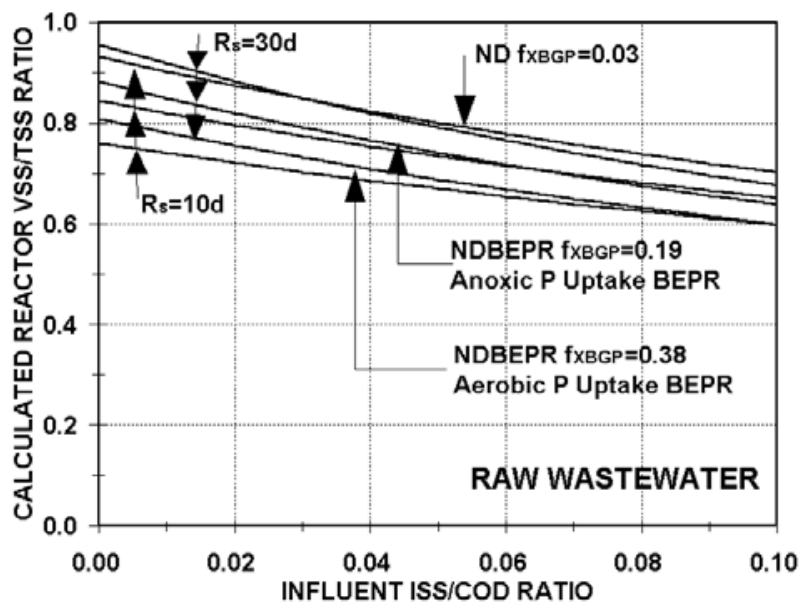

Figure 36

Calculated reactor VSS/TSS ratio for raw wastewater vs. influent $I S S / C O D$ ratio at 10 and $30 \mathrm{~d}$ sludge age for ND systems (no $B E P R)$ and NDBEPR systems with anoxic $\left(f_{X B G P}=0.19\right)$ and aerobic $\left(f_{X B G P}=0.38\right) P$ uptake $B E P R$

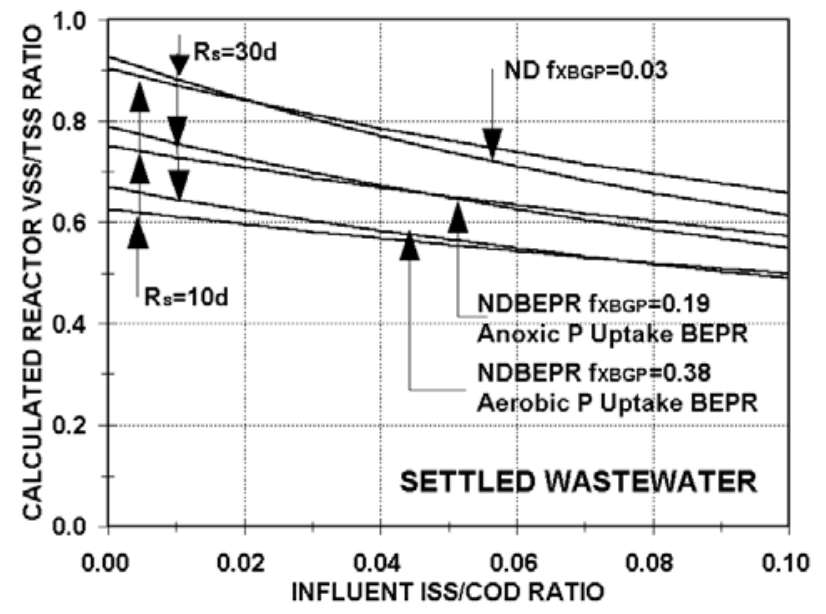

Figure 37

Calculated reactor VSS/TSS ratio for settled wastewater vs. influent ISS/COD ratio at 10 and $30 \mathrm{~d}$ sludge age for ND systems (no BEPR) and NDBEPR systems with anoxic $\left(f_{X B G P}=0.19\right)$ and aerobic $\left(f_{X B G P}=0.38\right) P$ uptake $B E P R$ difference in ISS/COD ratio is actually a small difference in ISS concentration, e.g. for the settled wastewater of $450 \mathrm{mgCOD} / \ell$ and ISS/COD ratios of 0.03 and 0.04 , the influent ISS concentration are 13.5 and $18 \mathrm{mgISS} / \ell$ respectively.

The ISS model indicates that for ND systems at short to intermediate sludge ages $(<15 \mathrm{~d})$ and NDBEPR systems at all sludge ages, the influent ISS plays a relatively small role in determining the reactor ISS mass. For these systems, the ISS mass is most strongly influenced by the active biomass, in particular the $\mathrm{P}$ content of the PAOs in NDBEPR systems. It is mainly for long sludge age ND systems that the influent ISS/COD ratio strongly influences the reactor VSS/TSS ratio (Figs. 20 and 33).

The conceptual basis for ISS model is accumulation of influent ISS in the reactor and the uptake of inorganic dissolved solids by the biomass, in particular the PAOs. If no other changes in IDS between influent and effluent take place (e.g. precipitation or dissolution), then the model predicted effluent IDS vs. sludge age for influent IDS of $400 \mathrm{mg} / \ell$ as shown in Fig. 38. It can be seen that the longer the sludge age, the less IDS is taken up. This is because the longer the sludge age, the longer the $\mathrm{OHO}$ and PAO endogenous processes have continued resulting in increased return of IDS back to the liquid phase. Uptake of IDS in NDBEPR systems is much higher than in ND systems due to the significantly higher inorganic content of PAOs and the return is much less because the endogenous rate of PAOs is very slow $(0.04 / \mathrm{d})$ compared with OHOs $(0.24 / \mathrm{d})$.

The ISS model shifts the uncertainty in design from selecting a reactor VSS/TSS ratio to selecting an influent ISS/COD ratio. As illustrated in Figs. 36 and 37, selection of an influent ISS/COD ratio for a particular activated sludge system fixes the reactor VSS/ TSS ratio, or, as was done in the past, selection of the reactor VSS/ TSS ratio presumed a certain influent ISS/COD ratio. Once a VSS/ TSS ratio is selected that conforms to the influent ISS/COD ratio and the system type (ND, anoxic or aerobic P uptake NDBERR), there is little difference between the empirical approach of assuming a constant VSS/TSS ratio with sludge age and the ISS model because of the insensitivity of the ratio to sludge age (Figs. 20 and 33, see below). Measurement of the influent ISS/COD ratio is possible, but a database of values needs to be assembled to develop greater confidence in the experimental method and realistic ranges of values. The greatest uncertainty in the model is selecting the $\mathrm{P}$ content of the PAOs $\left(\mathrm{f}_{\mathrm{XBGP}}\right)$. This is not a problem of the ISS model itself, but rather a deficiency in the BEPR models. With significant anoxic $\mathrm{P}$ uptake BEPR, the P content of the PAOs is uncertain (Fig. 24 ), and consequently also the biological $P$ removal. Factors that promote and suppress anoxic $\mathrm{P}$ uptake BEPR in NDBEPR systems are discussed by Sötemann et al. (2003). The conservative approach would be to assume $100 \%$ aerobic $P$ uptake BEPR, i.e. $\mathrm{f}_{\mathrm{XBG}}$ $=0.38 \mathrm{mgP} / \mathrm{mgPAOVSS}$, because this leads to the lowest VSS/ TSS ratio and hence the highest TSS mass in the reactor. This also gives the highest biological P removal that can be expected, and conforms with the steady state BEPR model of Wentzel et al. (1990) and the simulation models ASM2 (Henze et al. 1995) and UCTPHO (Wentzel et al. 1992).

The similarity of the empirical approach of assuming a constant VSS/TSS ratio with sludge age and the proposed ISS model is shown in Figs. 39 and 40 for raw and settled wastewater and ND and NDBEPR systems, the latter for $100 \%$ aerobic $P$ uptake $\left(\mathrm{f}_{\mathrm{XBGP}}\right.$ $=0.38 \mathrm{mgP} / \mathrm{mgPAOVSS})$. For the raw and settled wastewaters in Table 3 and influent ISS/COD ratios of 0.044 and $0.024 \mathrm{mgISS} /$ $\mathrm{mgCOD}$ respectively, yields from Eqs. (4) to (7) the reactor VSS/ TSS ratios listed in Table 4. Accepting these VSS/TSS ratios as constant with sludge age for the empirical approach, the VSS/TSS ratios and mass ISS in the reactor vs. sludge age calculated with the ISS model and the empirical approach are compared in Figs. 39 and 40. In Fig. 39, it can be seen that while the VSS/TSS ratio is significantly different for the different system types ranging from 0.60 to 0.83 , for each system the VSS/TSS ratio is approximately constant with sludge age. Closely constant VSS/TSS ratio with sludge age cannot be predicted by the ISS model considering influent ISS only for both ND and NDBEPR systems; an ISS content of OHOs (and PAOs if present) has to be accepted to achieve this. Figure 40 shows the same behaviour, that while different systems have significantly different masses of ISS in the biological reactor (per the $\mathrm{mgCOD}$ load per day on the reactor), the empirical approach of assuming a constant VSS/TSS ratio with sludge age and the ISS model predict virtually the same ISS mass in the reactor. Consequently, the problem with the empirical approach is not that it is incorrect, but that it provides no guidance on the VSS/ TSS ratio to select. The ISS model provides a basis for 


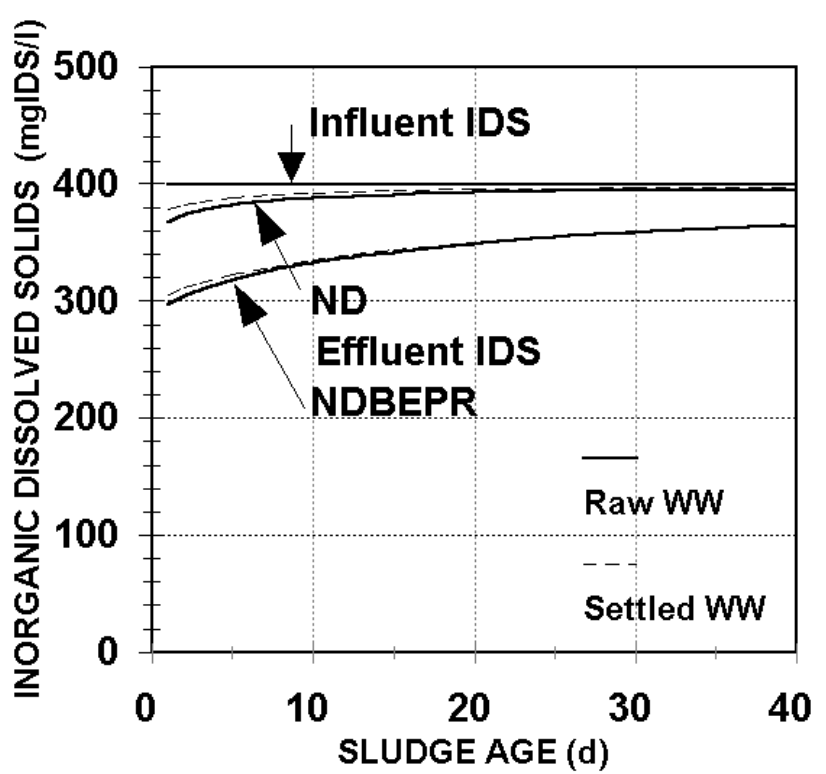

Figure 38

Calculated effluent inorganic dissolved solids (IDS) concentration vs. sludge age for raw and settled wastewater for an influent IDS concentration of $400 \mathrm{mg} / \mathrm{l}$ for ND and NDBEPR systems with aerobic $P$ uptake BEPR showing the extent of IDS uptake by

$\mathrm{OHOs}$ in ND and OHOs and PAOs in NDBEPR systems

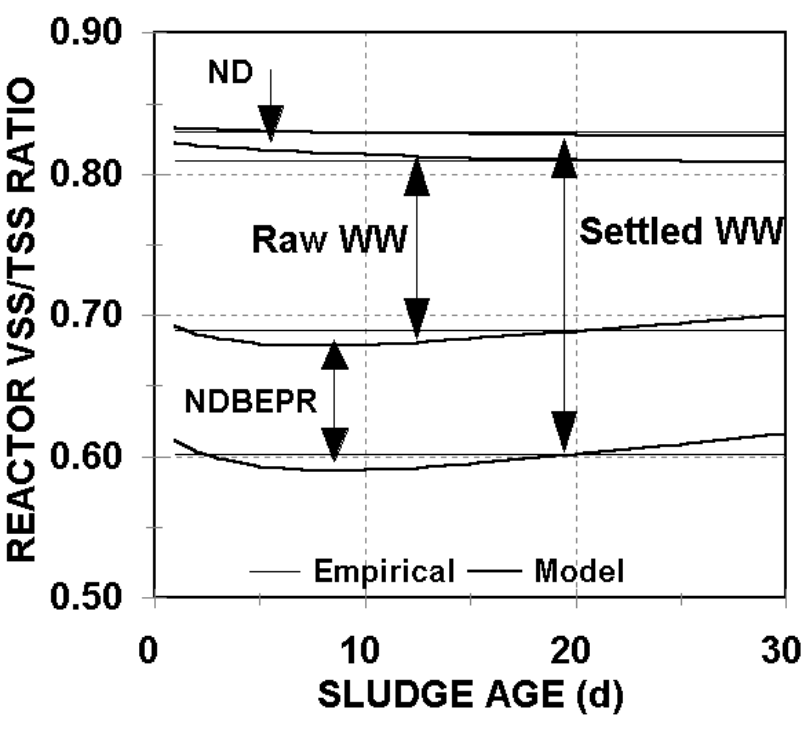

Figure 39

Reactor VSS/TSS ratio vs. sludge age showing similarity between ISS model predicted values and the former empirical approach (constant VSS/TSS ratio with sludge age) provided the correct VSS/TSS ratio is selected for the empirical approach
Figure 40

Mass of ISS in reactor per mass COD load on reactor per day vs. sludge age showing similarity between ISS model predicted values and the former empirical approach (constant VSS/TSS ratio with sludge age) provided the correct VSS/TSS ratio is selected for the empirical approach

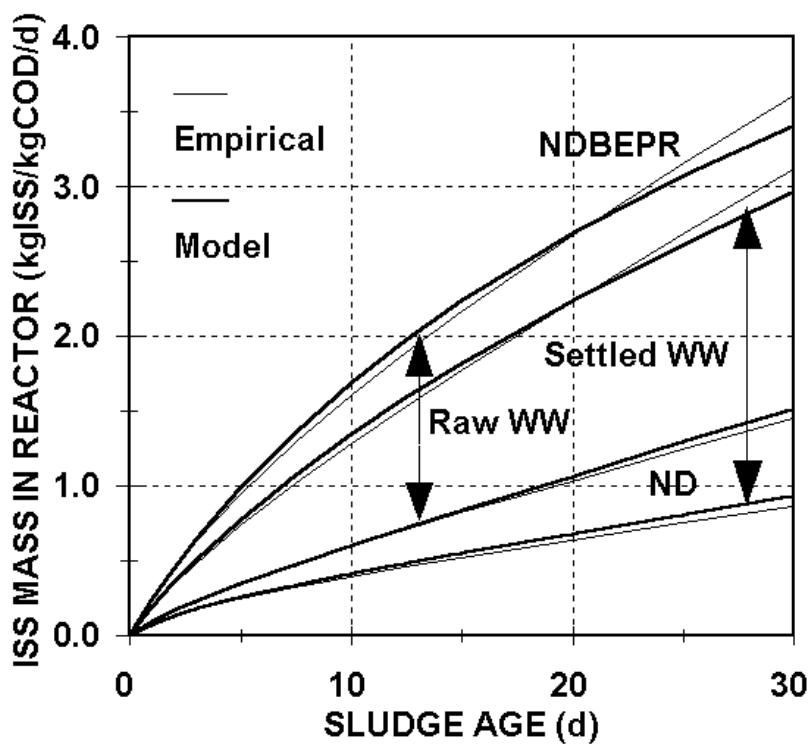

VSS/TSS ratio selection in conformity with influent wastewater characteristics and the type of activated sludge system.

The influent ISS/COD ratios calculated for the Mitchells Plain raw wastewater used in the laboratory systems and measured at the WWTP should be used with caution. Influent ISS/COD ratios need to be measured at a number of WWTPs to gain confidence in the analytical procedure and develop realistic ranges for this ratio.

\section{Conclusions}

A simple predictive model for estimating activated sludge reactor ISS (and hence TSS) concentration has been developed. It is based on the accumulation of influent ISS in the reactor, an ordinary heterotrophic organism (OHO) ISS content $\left(\mathrm{f}_{\mathrm{iOно}}\right)$ and a variable phosphate accumulating organism (PAO) ISS content $\left(\mathrm{f}_{\mathrm{ipAO}}\right)$ proportional to their $\mathrm{P}$ content $\left(\mathrm{f}_{\mathrm{XBGP}}\right)$ due to the uptake of inorganic dissolved solids (IDS) from the bulk liquid. This model can be readily integrated into existing steady state or dynamic simulation activated sludge models because these models formed the basis for determining the $\mathrm{OHO}$ and PAO ISS contents; and the $\mathrm{OHO}$ and PAO VSS concentrations in these models are known from the predictions. This will eliminate having to guess the reactor VSS/ TSS for design, but will require the influent ISS concentration to be known. Currently, this concentration is not measured as part of typical wastewater characterisation analyses. It is recommended that in future this be done with the glass fibre filtration and incineration method suggested.

The model was validated with data measured on 48 aerobic, 


\begin{tabular}{|c|c|c|c|c|c|c|}
\hline \multicolumn{7}{|c|}{$\begin{array}{l}\text { TABLE } 4 \\
\text { Calculated reactor VSS/TSS ratios with Eqs ( } 4 \text { to } 7 \text { ) for the raw and } \\
\text { settled wastewater characteristics in Table } 3 \text { for accepted } P \text { contents of } \\
\text { PAOs ( } f_{\text {XBGP }} \text { ) of ND (No BEPR), significant anoxic P uptake BEPR (Ax } \\
\text { BEPR) and aerobic P uptake BEPR (Aer BEPR) systems. }\end{array}$} \\
\hline Wastewater & \multicolumn{3}{|c|}{ Raw wastewater } & \multicolumn{3}{|c|}{ Settled wastewater } \\
\hline Influent ISS & \multicolumn{3}{|c|}{$0.044 \mathrm{mgISS} / \mathrm{mgCOD}$} & \multicolumn{3}{|c|}{$0.024 \mathrm{mgISS} / \mathrm{mgCOD}$} \\
\hline System Type & $\mathrm{ND}$ & Ax BEPR & Aer BEPR & ND & Ax BEPR & Aer BEPR \\
\hline $\mathrm{f}_{\mathrm{XBGP}}$ & 0.03 & 0.19 & 0.38 & 0.03 & 0.19 & 0.38 \\
\hline VSS/TSS & 0.81 & 0.75 & 0.69 & 0.83 & 0.71 & 0.60 \\
\hline
\end{tabular}

anoxic-aerobic nitrification denitrification (ND) and anaerobicanoxic-aerobic ND biological excess phosphorus removal (BEPR) systems operated in 21 investigations conducted in the Water Research Laboratory at the University of Cape Town over the past 15 years. These systems had sludge ages varying from 3 to 20 days, nominal hydraulic retention times from 9 to $48 \mathrm{~h}$ and were fed artificial or real wastewater from the same Mitchells Plain wastewater treatment plant.

From the enhanced PAO cultures investigation, the PAO ISS content $\left(\mathrm{f}_{\text {iPAO }}\right)$ for $100 \%$ aerobic $P$ uptake BEPR was calculated to be $1.30 \mathrm{mgISS} / \mathrm{mgPAOVSS}$. From the ND systems fed artificial or real wastewater, the OHO ISS content $\left(\mathrm{f}_{\mathrm{iOHO}}\right)$ was estimated to be around $0.15 \mathrm{mgISS} / \mathrm{mgOHOVSS}$. These calibrated $\mathrm{OHO}$ and PAO ISS contents were then applied to NDBEPR systems. For the systems exhibiting more than $90 \%$ aerobic $\mathrm{P}$ uptake BEPR, the predicted ISS correlated well with that measured. However, for systems exhibiting significant anoxic P uptake BEPR, for which the $\mathrm{P}$ content of the PAOs was lower, the correlation was poor. A linear relationship between the $\mathrm{P}$ and ISS contents of the PAOs was established i.e., $\mathrm{f}_{\text {iPAO }}=3.286\left(\mathrm{f}_{\text {XBGP }}-\mathrm{f}_{\text {XBGPBM }}\right)+\mathrm{f}_{\text {iPAOBM }}$ mgISS/ mgPAOVSS, where $f_{\mathrm{XBGP}}$ is the total P content of the PAO biomass, which significantly improved the correlation between calculated and measured reactor ISS concentrations. The 3.286 factor is the ISS content of the PAO intracellular polyphosphate which precipitates in the drying step of the TSS-VSS test procedure. This value correlates very closely with the $3.19 \mathrm{mgISS} / \mathrm{mgP}$ value theoretically estimated for polyphsphate and the 3.23 value included in ASM2 and 2d.

With the ISS contents of the OHO and PAOs established, the influent ISS concentration to account for the measured reactor ISS concentration was calculated as a ratio of the influent COD concentration $\left(\mathrm{X}_{\mathrm{Ioi}} / \mathrm{S}_{\mathrm{ti}}\right)$. For artificial feed systems, as expected, this ratio was very low (0.000 to 0.007$)$ and for the real wastewater systems, it varied between 0.01 and 0.05 for both ND and BEPR systems. Because the influent ISS concentrations were not measured in 18 of the 21 investigations, it was not possible to validate this rather large variation in influent ISS concentration. In 1 of the 3 investigations in which the influent ISS concentration was measured, a reasonably close correlation between calculated and measured influent ISS/COD ratio was obtained, i.e. 0.0267 (28.1 mgISS/ $\ell$ ) vs. 0.0308 ( $32.5 \mathrm{mg}$ ISS/ $\ell$ ) in I11 on a fully aerobic laboratory system. In the $2^{\text {nd }}$ and $3^{\text {rd }}$ investigations, the difference between calculated and measured influent ISS/COD ratio was much larger, i.e. in I18 on two 2M 1 /d NDBEPR plants 0.0213 (13.1 mgISS/ $/$ ) vs. 0.0413 (25.3 mgISS/ $\ell$ ) and in 112 on two laboratory ND systems, 0.0248 (12.2 mgISS/ $\ell$ ) vs. 0.0915 (47.0 mgISS/ $\ell$ ). Because influent ISS concentrations measured at the wastewater treatment plant with an improved analytical procedure yielded values in the range 0.040 to 0.050 , the very high measured value for I1 2 was almost certainly affected by bias resulting from the analytical procedure. The improved procedure reduced bias and increased precision of the measured ISS concentration.

The validated model reflected the observed reactor VSS/TSS sensitivity to sludge age and BEPR. Sludge age does not affect the VSS/TSS ratio much, whereas the the magnitude of $\mathrm{P}$ removal per influent $\mathrm{COD}$ ratio $(\Delta \mathrm{P} / \Delta \mathrm{COD})$ affects it significantly, decreasing as $\Delta \mathrm{P} / \Delta \mathrm{COD}$ increases.

Two parameters are required to use this reactor ISS concentration model: the influent ISS concentration; and the P content of the PAOs $\left(\mathrm{f}_{\mathrm{XBGP}}\right)$. The influent ISS concentration generally is not measured in wastewater characterisation analyses, so that, until a database is developed from which reasonable values can be estimated for raw or settled wastewaters, this concentration will need to be guessed. However, within a reasonable variation of influent ISS concentration, the $\Delta \mathrm{P} / \Delta \mathrm{COD}$ has the largest influence on the reactor ISS concentration and VSS/TSS ratio. Because the steady state and dynamic simulation models that include BEPR are generally based on the aerobic P uptake BEPR kinetics as developed by Wentzel et al. (1989b, 1992), the effective PAO P content is about $0.38 \mathrm{mgP} / \mathrm{mgPAOVSS}$. Sometimes significant anoxic $\mathrm{P}$ uptake BEPR takes place in NDBEPR systems, which reduces the BEPR, the $\triangle \mathrm{P} / \triangle \mathrm{COD}$, the $\mathrm{P}$ content of the PAOs (Ekama and Wentzel, 1999; Vermande et al., 2000), and hence also PAO ISS content.

The ISS model is integrated into the steady state model equations for organic solids (VSS) mass in the reactor including OHOs for ND systems, and additionally PAOs for NDBEPR systems. Until BEPR models can predict the reduction in P content of PAOs, and hence $\mathrm{P}$ removal, with significant anoxic $\mathrm{P}$ uptake $\mathrm{BEPR}$, it is recommended that the $\mathrm{P}$ content of PAOs $\left(\mathrm{f}_{\mathrm{XBGP}}\right)$, which is proportional to the ISS content of the PAOs, be selected to suit the system type to obtain an estimate of the reactor VSS/TSS ratio, i.e. 0.03 for ND, 0.19 for anoxic $\mathrm{P}$ uptake BEPR and 0.38 for aerobic $\mathrm{P}$ uptake BEPR.

Applying the calibrated ISS model to design showed that the reactor VSS/TSS ratio is not very sensitive to sludge age. This means that once an appropriate VSS/TSS ratio is selected to suit a particular wastewater and system type, it can be assumed in design to remain constant with sludge age. A constant VSS/TSS ratio with sludge age has been assumed in design for more than two decades, but now with the proposed ISS model is given an experimental and modelling basis. Some guidance for VSS/TSS ratio selection obtained from the ISS model is given. 


\section{Acknowledgements}

This research was supported by the Water Research Commission, National Research Foundation and University of Cape Town and is published with their permission. Gratitude is expressed to undergraduate BSc thesis students Wilma Legodi (2002) and Dumisani Nxumalo (2003), who for their BSc thesis projects developed and tested the glass fibre filter influent inorganic suspended solids (ISS) concentration measurement method and measured the influent ISS/COD ratio at some full-scale wastewater treatment plants in Cape Town with this method.

\section{References}

ARVIN E and KRISTENSEN GH (1985) Exchange of organics, phosphate and cations between sludge and water in biological phosphorus and nitrogen removal processes. Water Sci. Technol. 17 (11/12) 147-162.

BEEHARRY AO, WENTZEL MC and EKAMA GA (2001) Measurement of Active Organism Mass in Activated Sludge Systems Fed Different Unbiodegradable Particulate COD Fractions. Research Report W112, Dept. of Civil Eng., Univ. of Cape Town, Rondebosch, 7707, Cape, RSA

CLAYTON JA, EKAMA GA, WENTZEL MC and MARAIS GvR (1989) Denitrification Kinetics in Biological Nitrogen and Phosphorus Removal Activated Sludge Systems. Research Report W63, Dept. of Civil Eng., Univ. of Cape Town, Rondebosch, 7707, Cape, RSA.

COMEAU Y, HALL KJ, HANCOCK REW and OLDHAM WK (1985) Biochemical model for enhanced biological phosphorus removal. Procs. UBC Conference on New Directions and Research in Water Treatment and Residuals Management. June, Vancouver, Canada.

CRONJE GC, WENTZEL MC and EKAMA GA (2000) Measurement of Active Heterotrophic Organism Concentration in Nitrificationdenitrification Activated Sludge Systems. Research Report W102, Dept. of Civil Eng., Univ. of Cape Town, Rondebosch, 7707, Cape, RSA

DE VILLIERS ME, CASEY TG, WENTZEL MC and EKAMA GA (1994) the Effect of Nitrite and Nitrate Concentrations on Low F/m Filament Bulking in N Removal Activated Sludge Systems. Research Report W81, Dept. of Civil Eng., Univ. of Cape Town, Rondebosch, 7707, Cape, RSA.

EKAMA GA, SIEBRITZ IP and MARAIS GvR (1983) Considerations in the process design of nutrient removal activated sludge processes. Water Sci. Technol. 15 (3/4) 283-318.

EKAMA GA and WENTZEL MC (1999) Denitrification kinetics in biological N \& P removal activated sludge systems treating municipal wastewaters. Water Sci. Technol. 39 (6) 69-77.

FUKASE T, SHIBATA M and MIJAMI X (1982) Studies on the mechanism of biological phosphorus removal. Japan J. Water Pollut. Res. 5 309-317.

GAUDY AF and GAUDY ET (1980) Microbiology for Environmental Engineers. McGraw-Hill Book Co., NewYork.

GUJER W (1993) ASIM - Activated Sludge Simulation Program. EAWAG, Dubendorf, Switzerland.

GUJER W and LAWSON TA (1995) The implementation of biokinetics and conservation principles in ASIM. Water Sci Technol. 31 (2) 257 266.

HENZE M, GRADY CPL (Jnr), GUJER W, MARAIS GvR and MATSUO T (1987) Activated Sludge Model No1, IWA Scientific and Technical Report No 1, London.

HENZE M, GUJER W, MINO T, MATSUO T, WENTZEL MC and MARAIS GvR (1995) Activated sludge model No2, IWA Scientific and Technical Report No 3, London.

HENZE M, GUJER W, MINOT, MATSUO T, WENTZEL MC, MARAIS GvR and VAN LOOSDRECHT MCM (1999) Activated sludge model No2d. Water Sci Technol. 39 (1) 165-182.

HERCULES SM, WENTZEL MC and EKAMA GA (2002) Fullscale Demonstration of Filamentous Bulking Control At A Biological Nutrient Removal Activated Sludge Plant. Research Report W114, Dept. of Civil Eng., Univ. of Cape Town, Rondebosch, 7707, Cape, RSA.
HULSMAN A, CASEY TG, EKAMA GA, WENTZEL MC and MARAIS GvR (1992) the Effect of Type, Size, Position and Recycle Ratio of the Anoxic Zone on Low F/m Filament Bulking in Nitrogen Removal Activated Sludge Systems. Research Report W73, Dept. of Civil Eng., Univ. of Cape Town, Rondebosch, 7707, Cape, RSA.

JADAV M (1994) Accumulation of Inorganic Suspended Solids in Activated Sludge Systems. BSc thesis, Dept. of Civil Eng., Univ. of Cape Town, Rondebosch, 7707, Cape, RSA.

KASCHULA WA, EKAMA GA, PALMER SH, WENTZEL MC and BIRCH RR (1993) the Effect of Alternative Detergent Builders on the Nutrient Removal Activated Sludge Sewage Treatment Process. Research Report W78, Dept. of Civil Eng., Univ. of Cape Town, Rondebosch, 7707, Cape, RSA.

KETLEY DA, CASEY TG, EKAMA GA, WENTZEL MC and MARAIS GvR (1991) the Effect of Fully Anoxic Conditions and Frequency of Exposure to Anoxic and Aerobic Conditions on the Growth of Low F/ M Filaments in Nitrogen Removal Systems. Research Report W68, Dept. of Civil Eng., Univ. of Cape Town, Rondebosch, 7707, Cape, RSA.

LEE B-J, WENTZEL MC and EKAMA GA (2003) Batch Test for Measurement of Ordinary Heterotrophic Organism Active Mass in Activated Sludge Mixed Liquor. Research Report W118, Dept. of Civil Eng., Univ. of Cape Town, Rondebosch, 7707, Cape, RSA

MELLIN HKO, LAKAY MT, WENTZEL MC and EKAMA GA (1998) the Effect of High Temperatures $\left(30^{\circ} \mathrm{c}\right)$ on Biological Nutrient Removal Performance. Research Report W91, Dept. of Civil Eng., Univ. of Cape Town, Rondebosch, 7707, Cape, RSA

MULLER A, WENTZEL MC and EKAMA GA (2003) Measurement of Ordinary Heterotrophic Organism Anoxic Yield in Anoxic-aerobic Activated Sludge Systems. Research Report W119, Dept. of Civil Eng., Univ. of Cape Town, Rondebosch, 7707, Cape, RSA

MUSVOTOE V,CASEY TG, WENTZEL MC, EKAMA GA and MARAIS GvR (1992) the Effect of Large Anoxic Mass Fractions and Concentrations of Nitrate and Nitrite in the Primary Anoxic Zone on Low F/ m Filament Bulking in Nutrient Removal Activated Sludge Systems. Research Report W77, Dept. of Civil Eng., Univ. of Cape Town, Rondebosch, 7707, Cape, RSA.

PILSON RA, WENTZEL MC, CASEY TG and EKAMA GA (1995) Denitrification Kinetics and AA Filament Bulking in Biological Nutrient Removal System At $14^{\circ} \mathrm{C}$. Research Report W86, Dept. of Civil Eng., Univ. of Cape Town, Rondebosch, 7707, Cape, RSA

POWER SPB, EKAMA GA, WENTZEL MC and MARAIS GvR (1992) Chemical Phosphorus Removal From Municipal Wastewater by the Addition of Waste Alum Sludge to the Activated Sludge System. Research Report W66, Dept. of Civil Eng., Univ. of Cape Town, Rondebosch, 7707, Cape, RSA.

SNEYDERS MJ, WENTZEL MC and EKAMA GA (1998) the Effect of Dosing Unstabilised Landfill Leachate Into A Nutrient Removal Activated Sludge System. Research Report W95, Dept. of Civil Eng., Univ. of Cape Town, Rondebosch, 7707, Cape, RSA

SÖTEMANN SW, VERMANDE SM, WENTZEL MC and EKAMA GA (2003) Comparison of the performance of an external nitrification biological nutrient removal activated sludge system with a UCT biological nutrient removal activated sludge system. Water SA, WISA 2002 edn, 105-113.

TSAI M-W, WENTZEL MC and EKAMA GA (2002) Filamentous Bulking Control with Redox Potential. Research Report W115, Dept. of Civil Eng., Univ. of Cape Town, Rondebosch, 7707, Cape, RSA

UBISI MF, WENTZEL MC and EKAMA GA (1997) Organic and Inorganic Components of Activated Sludge Mixed Liquor. Research Report W94, Dept. of Civil Eng., Univ. of Cape Town, Rondebosch, 7707, Cape, RSA

VERMANDES, LAKAY MT, WENTZEL MC, EKAMA and AGUILERASORIANO G (2000) Comparison of Aerobic and Anoxic-aerobic P Uptake in Biological Nutrient Removal Systems. Research Report W103, Dept. of Civil Eng., Univ. of Cape Town, Rondebosch, 7707, Cape, RSA

WARBURTONCA, LAKAY MT, CASEYTG, EKAMA GA, WENTZEL MC and MARAIS GvR (1991) the Effect of Sludge Age and Aerobic Mass Fraction on Low F/m Filament Bulking in Intermittent Aeration Nitrogen Removal Systems. Research Report W65, Dept. of Civil Eng., Univ. of Cape Town, Rondebosch, 7707, Cape, RSA. 
WENTZEL MC, EKAMA GA, LOEWENTHAL RE, DOLD PL and MARAIS GvR (1989a) Enhanced polyphosphate organism cultures in activated sludge systems Part II - Experimental behaviour. Water SA 15 (2) $71-88$.

WENTZEL MC, DOLD PL, EKAMA GA and MARAIS GvR (1989b) Enhanced polyphosphate organism cultures in activated sludge systems Part III - Kinetic model. Water SA 15 (2) 89-102.

WENTZEL MC, EKAMA GA, DOLD PL and MARAIS GvR (1990) Biological excess phosphorus removal - Steady state process design. Water SA 16 (1) 29-48.
WENTZEL MC, EKAMA GA and MARAIS GvR (1992) Processes and modelling of nitrification dentirification biological excess phosphorus removal systems - A review. Water Sci Technol. 25 (6) 59-82.

WENTZEL MC, UBISI MF, LAKAY MT and EKAMA GA (2002) Incorporation of inorganic material in anoxic/aerobic activated sludge system mixed. Water Res. 36 (20) 5074-5082.

WRC (1984) Theory, Design and Operation of Biological Nutrient Removal Activated Sludge Processes, ISBN 090835613 7, Water Research Commission, Private Bag X03, Gezina 0031, RSA. 